\title{
Determination of the Mixing Thermodynamic Properties of Liquid Ternary Alloys by Fitting the Knudsen Effusion Mass Spectrometric Data to the Redlich-Kister-Muggianu Sub-Regular Solution Model
}

\author{
L. Bencze ${ }^{1, *}$ and A. Popovic ${ }^{2}$ \\ ${ }^{1}$ Eötvös Loránd University, Deptarment of Physical Chemistry, H-1117 Budapest, Pázmány Péter sétány 1/A, Hungary \\ ${ }^{2}$ Jozef Stefan Institute, Jamova 39, SI-1000 Ljubljana, Slovenia
}

\begin{abstract}
We discuss the vaporisation of four liquid ternary-alloy systems, namely, Cu-In-Sn, Ag-In-Sn, Al-Cu-Sn and $\mathrm{Cu}-\mathrm{Sb}-\mathrm{Sn}$, on the basis of our previous Knudsen effusion mass spectrometric (KEMS) investigations of these systems. The thermodynamic activities and the thermodynamic functions (Gibbs energy, enthalpy, entropy) of mixing were determined using selected standard KEMS procedures (i.e., Simple Pressure Calibration Method (SPC), Oligomer Composition Change Method (OCC), Isothermal Evaporation Method (IEM) and Gibbs-Duhem Ion Intensity Ratio Method (GD-IIR)). In addition, the same thermodynamic quantities, as well as the so-called ternary interaction (L-) parameters, were also obtained from the composition dependence of the measured ion-intensity ratios using a new mathematical procedure (RKM-KEMS). The essence of this new procedure is the fitting of the measured intensity-ratio data were to the Redlich-Kister-Muggianu (RKM) sub-regular solution model, and this model is valid for many liquid ternary alloys, including the systems reviewed here. A full description of the mathematical derivation of RKM-KEMS is given in this work. The primary and intermediate data, obtained directly from the multiple-regression as output data, are the RKM ternary interaction L-parameters. From these quantities, the integral molar excess Gibbs energy, the excess chemical potentials, the activity coefficients and the activities were evaluated in this order. In addition, using the temperature dependence of activities, the integral and partial molar excess enthalpies and entropies could also be determined. The thermodynamic data obtained with the above-mentioned conventional KEMS methods and with the new RKM-KEMS procedure were compared and a good agreement was obtained for the systems studied.
\end{abstract}

Keywords: Review, Knudsen Effusion Mass Spectrometry (KEMS), Thermochemistry, Modelling, High temperature, Vaporisation, $\mathrm{Cu}-\mathrm{In}$-Sn alloy, Ag-In-Sn alloy, Al-Cu-Sn alloy, $\mathrm{Cu}-\mathrm{Sb}-\mathrm{Sn}$ alloy.

\section{INTRODUCTION}

The search to find a replacement for lead solder in the electronics industry has expanded significantly during the past decade. According to the European Directive covering Waste from Electrical and Electronic Equipment (the WEEE Directive of 2000) it was proposed to ban completely the use of lead solders after January 2008. However, in order to design new, lead-free soldering alloys, an understanding of the thermodynamic and mechanical properties of new, candidate alloys is necessary. It is now widely agreed that there will be no single drop-in replacement for lead-tin solders and that the final choice of the solder material will be application-dependent. Thus, a number of possible replacements are being investigated, including binary, ternary and even quaternary alloy systems composed of Sn, $\mathrm{Sb}, \mathrm{Cu}, \mathrm{Ag}, \mathrm{In}, \mathrm{Zn}, \mathrm{Ni}, \mathrm{Au}$ and $\mathrm{Pd}$. Indium is included here due to its low melting point, while palladium, gold, copper and nickel also represent possible substrates. A full thermodynamic description of an alloy system is possible if

*Address correspondence to this author at the Eötvös Loránd University, Dept. of Physical Chemistry, H-1117 Budapest, Pázmány Péter sétány 1/A, Hungary; Tel: +36 1 3722500/1571; Fax: +36 1 3722592;

E-mail: bencze@chem.elte.hu the Gibbs energy of all the phases present in equilibrium for a given temperature is known. Using Knudsen effusion mass spectrometry (KEMS) the thermodynamic properties of mixing can be determined. In contrast to binary alloys, there is a lack of thermodynamic data concerning ternary alloys. Our former KEMS studies on Cu-In-Sn [1], Ag-In-Sn [2], $\mathrm{Al}-\mathrm{Cu}-\mathrm{Sn}$ [3], $\mathrm{Cu}-\mathrm{Sb}-\mathrm{Sn}$ [4] liquid ternary systems in the framework of the EU's COST 531 and MP0602 actions could improve this circumstance, at least to some extent. In 2001 Miki et al., [5] were able to show that by using the Redlich-Kister-Muggianu (RKM) sub-regular solution model for liquid alloys they could obtain the ternary interaction parameters directly from mass spectrometric measurements. However, Miki et al., [5], as a simplification, described the mixing thermodynamic properties of the Ag-In-Sn system using only one kind of ternary $L$-parameter instead of the generally accepted three different parameters. In addition, Miki et al., [5] determined the single ternary $L$-parameter and the corresponding thermodynamic data measuring only the $\mathrm{Ag}^{+}$to $\mathrm{In}^{+}$ion-intensity ratio without trying to obtain the same parameters from both the $\mathrm{Ag}^{+}$to $\mathrm{Sn}^{+}$and the $\mathrm{In}^{+}$to $\mathrm{Sn}^{+}$ ratios since they did not measure the ion intensities of all the three components. In addition, Schmidt and Tomiska [6], independently of Miki et al., [5], developed a similar mass spectrometric regression method, not by using the RKM-type 
power series on the composition, but by using the so-called thermodynamic adoptive parameter (TAP) series for the description of the individual phases. In our previous article [1], we applied Miki' s [5] method to the study of the $\mathrm{Cu}-\mathrm{In}-\mathrm{Sn}$ system using only the $\mathrm{Cu}+$ to $\mathrm{Sn}+$ ion-intensity ratio and the RKM-type power series, but supplemented the mathematical derivation by assuming three different ternary-interaction parameters, in accordance with the theory. In the study of the Ag-In-Sn system [2], our aim was to elaborate the equivalent mathematical regression procedures using either the $\mathrm{Ag}+$ to $\mathrm{Sn}+$ or the $\mathrm{Ag}+$ to $\mathrm{In}+$ ion-intensity ratios as independent input data, to examine the agreement between the thermodynamic data obtained using both ion intensity ratios. Certainly, in a ternary alloy system there are three variations of ion-intensity ratios if only atomic ions are observed and, in theory, all of them can be used independently to obtain the mixing thermodynamic data. In addition to the RKM-modelling, we confirmed the reliability of the data using standard, model-free KEMS procedures (Isothermal Evaporation Method (IEM), Gibbs-Duhem Ion Intensity Ratio Method (GD-IIR)) as well. Nevertheless, modelling increases the value of KEMS since the thermodynamic data can also be derived from the equations for those compositions and temperatures that were not studied directly during the measurements. In addition to the RKM model, there are other ternary-mixture models (Chow-, Hillert-, Toop-Bonnier-, Kohler-, Colinet models, etc.) in the literature [7-10], but many experimental data in the literature confirm that, for liquid ternary alloys, the data provided by the RKM model seems to be the closest to the true, model-free experimental data. Therefore, we fitted the raw experimental data (ion-intensity ratios $v s$. composition and temperature) of liquid ternary alloys exclusively to the RKM model in our earlier papers dealing with such systems [1-4]. Miki et al., [5] also fitted their measured data only to this model. Nevertheless, a future elaboration of a link between the KEMS results and the other ternary mixture models could be advantageous.

\section{EXPERIMENTAL}

\section{Instrumental}

In our KEMS studies a Nier-type, low-resolution, homemade, magnetic mass spectrometer was used in combination with a Knudsen evaporator consisting a single alumina Knudsen cell. A general description of KEMS can be found in Ref. [11]. In a typical experiment the sample is heated in the Knudsen cell to the desired temperature. The equilibrium vapour, effusing through a small cell-orifice, is admitted into the ionisation chamber of the ion source where the gaseous species are ionised by electron impact. During our investigations of liquid alloys we applied $30 \mathrm{eV}$ as the ionising electron energy. The ions are separated according to their mass - to - charge ratio in the magnetic analyser and their intensities are measured using the electron multiplier. We operated the ETP-type, active-film multiplier in the counting mode at a $-3.0 \mathrm{kV}$ feed. For a detailed description of our experimental setup, see Ref. [12]. In such an arrangement, above the condensed sample, the equilibrium vapour pressure $\left(p_{\mathrm{j}}\right)$ of the molecular species ' $j$ ', within the Knudsen cell, can be obtained using the well-known Eqn. [1]

$p_{\mathrm{j}}=\frac{K \cdot T}{\sigma_{\mathrm{j}}} \sum_{k} \frac{I_{\mathrm{jk}}^{+}}{\eta_{\mathrm{k}} \cdot \gamma_{\mathrm{k}}}$ where $I_{\mathrm{jk}}^{+}$is the intensity of the ion $k$ formed from the molecular species $j ; T$ is the absolute temperature of the Knudsen cell; $K$ is the general sensitivity constant of the instrument; $\sigma_{j}$ is the ionisation cross-section of the molecular species $j$ for the ionising electron energy used; $\eta_{\mathrm{k}}$ and $\gamma_{\mathrm{k}}$ are the isotope abundance and the multiplier efficiency for the ion $k$; respectively. In the counting mode and optimal supply voltage of the multiplier (on the 'plateau' of the characteristics curve) $\gamma_{\mathrm{k}}$ was the same for all types of ions. The notation $I_{\mathrm{jk}}^{+}$ assumes that only one kind of isotopic ion is measured for each type of ion $(k)$, so that $k$ denotes the different stoichiometry (parent and all fragments) of the ions rather than the different isotopes. If all the isotopes are used in Eqn. (1), then $\eta_{\mathrm{k}}$ is not present in the formula.

Below, instead of the notation $I_{\mathrm{AA}}^{+}$, i.e., the intensity of ion $\mathrm{A}^{+}$originating from species $\mathrm{A}(\mathrm{g})$, as a simplification, we shall use the notation $I_{\mathrm{A}}$, since, except for $\mathrm{Sb}$ it is mostly atomic species that are present in the equilibrium vapour over the studied metals.

We can obtain the variation of the vapour-pressure ratio of the two given species with temperature by measuring only the ion-intensity ratio without any explicit knowledge of the values of the parameters in Eqn. (1). In using such relative KEMS methods it is not necessary to calculate the vapour pressures of the components for the determination of the activities and the mixing thermodynamic quantities, since these quantities, in certain cases, can be obtained from the measured ion intensities or rather from the ion-intensity ratios alone, directly. This important feature of KEMS, previously realized by many sub-methods, makes it an efficient technique for measuring the activities and thermodynamic quantities of binary systems [13].

\section{Sample Preparation and Measuring Procedure}

During the investigations of the ternary alloys, weighed amounts of powdered pure metals (obtained from SIGMAALDRICH) were mixed and pressed in a cup at room temperature to make hard pellets. We always made exactly $500 \mathrm{mg}$ of the mixture. While pressing the powder mixture for some seconds at room temperature with a high pressure the small grains, were partly sintered. Then the heterogeneous sintered sample (a pellet) was loaded into a cylindrical alumina cell (typically $10 \mathrm{~mm}$ long, $10 \mathrm{~mm}$ in diameter) having a channel-type orifice with a diameter of $0.55 \mathrm{~mm}$. The cell was then inserted into the Knudsen evaporator [12] and evacuated to high vacuum, after which it was heated to $1200{ }^{\circ} \mathrm{C}$ at $20{ }^{\circ} \mathrm{C} / \mathrm{min}$. Due to the roomtemperature sintering of the small grains, the mixtures melted at around their true liquidus temperatures, which are always below $1000{ }^{\circ} \mathrm{C}$ for all compositions of the alloy systems studied so far [1-4]. Soon after reaching $1200{ }^{\circ} \mathrm{C}$ and the thermodynamic equilibrium, the intensities of the most abundant isotopic ions originating from the three components, i.e., ${ }^{27} \mathrm{Al}^{+},{ }^{63} \mathrm{Cu}^{+}$and ${ }^{120} \mathrm{Sn}^{+}$for $\mathrm{Al}-\mathrm{Cu}-\mathrm{Sn}$ system, were measured at every $10{ }^{\circ} \mathrm{C}$ down to $1000^{\circ} \mathrm{C}$. For the isothermal evaporation experiments also, alumina cells were used, but with different orifice geometries. 


\section{RESULTS AND DISCUSSION}

\section{Theoretical Introduction}

(Determination of the thermodynamic properties of the mixing of ternary liquid mixtures using selected conventional KEMS methods and also using a new mathematical procedure (RKM-KEMS) that fits the raw KEMS data to the Redlich-Kister-Muggianu sub-regular solution model).

\section{The RKM-KEMS Procedure}

The excess Gibbs energy of ternary liquid mixtures, taking both the binary and ternary interactions into account, can be described as random mixtures of the components $A, B$ and $C$ by a sub-regular, solution-type model, after Muggianu [14] as in Eqn. [2]:

$$
\begin{aligned}
& G^{\mathrm{E}}=X_{\mathrm{A}} X_{\mathrm{B}} \sum_{i=0}^{n_{\mathrm{AB}}} L_{\mathrm{AB}}^{(i)}\left(X_{\mathrm{A}}-X_{\mathrm{B}}\right)^{i}+X_{\mathrm{A}} X_{\mathrm{C}} \sum_{i=0}^{n_{\mathrm{AC}}} L_{\mathrm{AC}}^{(i)}\left(X_{\mathrm{A}}-X_{\mathrm{C}}\right)^{i}+ \\
& +X_{\mathrm{B}} X_{\mathrm{C}} \sum_{i=0}^{n_{\mathrm{BC}}} L_{\mathrm{BC}}^{(i)}\left(X_{\mathrm{B}}-X_{\mathrm{C}}\right)^{i}+X_{\mathrm{A}} X_{\mathrm{B}} X_{\mathrm{C}}\left[L_{\mathrm{ABC}}^{(0)} X_{\mathrm{A}}+L_{\mathrm{ABC}}^{(1)} X_{\mathrm{B}}+L_{\mathrm{ABC}}^{(2)} X_{\mathrm{C}}\right]
\end{aligned}
$$

where $X_{\mathrm{A}}, X_{\mathrm{B}}$ and $X_{\mathrm{C}}$ are the mole fractions, and the $L$ parameters are the binary and ternary interaction parameters. The binary $L$-parameters are the same as those in the three boundary binary systems. In a real system the notations $A, B$ and $C$ must be replaced with the formulae of the real components (in our case the metallic elements) in alphabetical order, i.e., $A=\mathrm{Al}, B=\mathrm{Cu}$ and $C=\mathrm{Sn}$. While the number of binary $L$-parameters $\left(n_{\mathrm{AB}}, n_{\mathrm{AC}}\right.$ and $\left.n_{\mathrm{BC}}\right)$ used in Eqn. (2) depends on the best fit for the measured $G^{\mathrm{E}}$ binary data $v s$. composition, the number of ternary $L$-parameters is strictly three in the RKM model. Furthermore, in simplified cases only one ternary $L_{\mathrm{ABC}}$ is assumed (see Miki et al.'s assumption $\left(L_{\mathrm{ABC}}^{(0)}=L_{\mathrm{ABC}}^{(1)}=L_{\mathrm{ABC}}^{(2)}=L_{\mathrm{ABC}}\right)$ in Ref. [5]).

It is known from classical thermodynamics that in a single-phase, i.e., homogeneous, ternary system, the following relationships are valid:

$\left(\frac{\partial G^{\mathrm{E}}}{\partial X_{\mathrm{A}}}\right)_{X_{\mathrm{C}}}=\mu_{\mathrm{A}}^{\mathrm{E}}-\mu_{\mathrm{B}}^{\mathrm{E}}=R T \ln \left(\frac{\gamma_{\mathrm{A}}}{\gamma_{\mathrm{B}}}\right)$

$\left(\frac{\partial G^{\mathrm{E}}}{\partial X_{\mathrm{A}}}\right)_{X_{\mathrm{B}}}=\mu_{\mathrm{A}}^{\mathrm{E}}-\mu_{\mathrm{C}}^{\mathrm{E}}=R T \ln \left(\frac{\gamma_{\mathrm{A}}}{\gamma_{\mathrm{C}}}\right)$

$\left(\frac{\partial G^{\mathrm{E}}}{\partial X_{\mathrm{B}}}\right)_{X_{\mathrm{A}}}=\mu_{\mathrm{B}}^{\mathrm{E}}-\mu_{\mathrm{C}}^{\mathrm{E}}=R T \ln \left(\frac{\gamma_{\mathrm{B}}}{\gamma_{\mathrm{C}}}\right)$

Selecting Eqn. (4), based on thermodynamic and KEMS relationships, further rearrangements can be performed, as follows:

$$
\begin{aligned}
& \left(\frac{\partial G^{\mathrm{E}}}{\partial X_{\mathrm{A}}}\right)_{X_{\mathrm{B}}}=\mu_{\mathrm{A}}^{\mathrm{E}}-\mu_{\mathrm{C}}^{\mathrm{E}}=R T \ln \left(\frac{\gamma_{\mathrm{A}}}{\gamma_{\mathrm{C}}}\right)=R T \ln \left(\frac{a_{\mathrm{A}} X_{\mathrm{C}}}{a_{\mathrm{C}} X_{\mathrm{A}}}\right)=R T \ln \left(\frac{p_{\mathrm{A}} p_{\mathrm{C}}^{*} X_{\mathrm{C}}}{p_{\mathrm{C}} p_{\mathrm{A}}^{*} X_{\mathrm{A}}}\right)= \\
& =R T \ln \left(\frac{K I_{\mathrm{A}} T X_{\mathrm{C}} p_{\mathrm{C}}^{*} \sigma_{\mathrm{C}} \eta_{\mathrm{C}}}{K I_{\mathrm{C}} T X_{\mathrm{A}} p_{\mathrm{A}}^{*} \sigma_{\mathrm{A}} \eta_{\mathrm{A}}}\right)=R T \ln \left(\frac{I_{\mathrm{A}} X_{\mathrm{C}}}{I_{\mathrm{C}} X_{\mathrm{A}}}\right)+R T \ln \left(\frac{p_{\mathrm{C}}^{*} \sigma_{\mathrm{C}} \eta_{\mathrm{C}}}{p_{\mathrm{A}}^{*} \sigma_{\mathrm{A}} \eta_{\mathrm{A}}}\right)= \\
& =R T \ln \left(\frac{I_{\mathrm{A}} X_{\mathrm{C}}}{I_{\mathrm{C}} X_{\mathrm{A}}}\right)+C_{\mathrm{ABC}\left(\mathrm{A}^{+} / \mathrm{C}^{+}\right)}=R T\left[\ln \left(\frac{I_{\mathrm{A}}}{I_{\mathrm{C}}}\right)-\ln \left(\frac{X_{\mathrm{A}}}{X_{\mathrm{C}}}\right)\right]+C_{\mathrm{ABC}\left(\mathrm{A}^{+} / \mathrm{C}^{+}\right)}
\end{aligned}
$$

where $C_{\mathrm{ABC}\left(\mathrm{A}^{+} / \mathrm{C}^{+}\right)}$, which does not depend on the composition but on the temperature and the ionising electron energy only, can be expressed as follows:

$$
\begin{aligned}
& C_{\mathrm{ABC}\left(\mathrm{A}^{+} / \mathrm{C}^{+}\right)}=R T \ln \left(\frac{p_{\mathrm{C}}^{*} \sigma_{\mathrm{C}} \eta_{\mathrm{C}}}{p_{\mathrm{A}}^{*} \sigma_{\mathrm{A}} \eta_{\mathrm{A}}}\right)=-R T \ln \left(p_{\mathrm{A}}^{*}\right)-\left(-R T \ln \left(p_{\mathrm{C}}^{*}\right)\right)-R T \ln \left(\frac{\sigma_{\mathrm{A}} \eta_{\mathrm{A}}}{\sigma_{\mathrm{C}} \eta_{\mathrm{C}}}\right)= \\
& \approx \Delta_{\text {vap }} G_{\mathrm{A}}^{*}-\Delta_{\text {vap }} G_{\mathrm{C}}^{*}+R T \ln \left(\frac{k_{\mathrm{A}}}{k_{\mathrm{C}}}\right)
\end{aligned}
$$

where $\Delta_{\mathrm{vap}} G_{\mathrm{A}}^{*}$ denotes the standard Gibbs energy change of the evaporation reaction over the pure component $\mathrm{A}$. The asterisk $(*)$ denotes the pure component and $k_{\mathrm{A}}$ denotes the partial sensitivity constant of the KEMS apparatus for the gas $\mathrm{A}(\mathrm{g})$ and for the selected isotopic ion of $\mathrm{A}^{+}$originating from $\mathrm{A}(\mathrm{g})$. Similar rearrangements can be performed using Eqns. (3) and (5) as well. Note that the quantity of $C_{\mathrm{ABC}}\left(\mathrm{A}^{+} / \mathrm{C}^{+}\right.$) remains constant if it is only the composition that is varied (if the temperature and the ionising electron energy remain the same) during the investigations.

Since Eqn. (2) expresses $G^{\mathrm{E}}$ as a function of composition, $\left(\partial G^{\mathrm{E}} / \partial X_{\mathrm{A}}\right)_{X_{\mathrm{B}}}$ can be expressed analytically using the standard mathematical differentiation rules. This results in:

$$
\begin{aligned}
& \left(\frac{\partial G^{\mathrm{E}}}{\partial X_{\mathrm{A}}}\right)_{X_{\mathrm{B}}}=-Y_{\mathrm{ABC}\left(\mathrm{A}^{+} / \mathrm{C}^{+}\right)}+L_{\mathrm{ABC}}^{(0)}\left(2 X_{\mathrm{C}}-X_{\mathrm{A}}\right) X_{\mathrm{A}} X_{\mathrm{B}}+ \\
& +L_{\mathrm{ABC}}^{(1)}\left(X_{\mathrm{C}}-X_{\mathrm{A}}\right)\left(X_{\mathrm{B}}\right)^{2}+L_{\mathrm{ABC}}^{(2)}\left(X_{\mathrm{C}}-2 X_{\mathrm{A}}\right) X_{\mathrm{C}} X_{\mathrm{B}}
\end{aligned}
$$

where $Y_{\mathrm{ABC}}\left(\mathrm{A}^{+} / \mathrm{C}^{+}\right.$, which includes only binary terms, is as follows:

$$
\begin{aligned}
& Y_{\mathrm{ABC}\left(\mathrm{A}^{+} C^{+}\right)} \equiv \\
& \quad-\left\{X_{\mathrm{B}}\left[L_{\mathrm{AB}}^{(0)}+L_{\mathrm{AB}}^{(1)}\left(X_{\mathrm{A}}-X_{\mathrm{B}}\right)+L_{\mathrm{AB}}^{(2)}\left(X_{\mathrm{A}}-X_{\mathrm{B}}\right)^{2}+L_{\mathrm{AB}}^{(3)}\left(X_{\mathrm{A}}-X_{\mathrm{B}}\right)^{3}\right]+\right. \\
& \quad+X_{\mathrm{A}} X_{\mathrm{B}}\left[L_{\mathrm{AB}}^{(1)}+2 L_{\mathrm{AB}}^{(2)}\left(X_{\mathrm{A}}-X_{\mathrm{B}}\right)+3 L_{\mathrm{AB}}^{(3)}\left(X_{\mathrm{A}}-X_{\mathrm{B}}\right)^{2}\right]+ \\
& \quad+X_{\mathrm{C}}\left[L_{\mathrm{AC}}^{(0)}+L_{\mathrm{AC}}^{(1)}\left(X_{\mathrm{A}}-X_{\mathrm{C}}\right)+L_{\mathrm{AC}}^{(2)}\left(X_{\mathrm{A}}-X_{\mathrm{C}}\right)^{2}+L_{\mathrm{AC}}^{(3)}\left(X_{\mathrm{A}}-X_{\mathrm{C}}\right)^{3}\right]- \\
& \quad-X_{\mathrm{A}}\left[L_{\mathrm{AC}}^{(0)}+L_{\mathrm{AC}}^{(1)}\left(X_{\mathrm{A}}-X_{\mathrm{C}}\right)+L_{\mathrm{AC}}^{(2)}\left(X_{\mathrm{A}}-X_{\mathrm{C}}\right)^{2}+L_{\mathrm{AC}}^{(3)}\left(X_{\mathrm{A}}-X_{\mathrm{C}}\right)^{3}\right]+ \\
& \quad+X_{\mathrm{A}} X_{\mathrm{C}}\left[2 L_{\mathrm{AC}}^{(1)}+4 L_{\mathrm{AC}}^{(2)}\left(X_{\mathrm{A}}-X_{\mathrm{C}}\right)+6 L_{\mathrm{AC}}^{(3)}\left(X_{\mathrm{A}}-X_{\mathrm{C}}\right)^{2}\right]- \\
& \quad-X_{\mathrm{B}}\left[L_{\mathrm{BC}}^{(0)}+L_{\mathrm{BC}}^{(1)}\left(X_{\mathrm{B}}-X_{\mathrm{C}}\right)+L_{\mathrm{BC}}^{(2)}\left(X_{\mathrm{B}}-X_{\mathrm{C}}\right)^{2}+L_{\mathrm{BC}}^{(3)}\left(X_{\mathrm{B}}-X_{\mathrm{C}}\right)^{3}\right]+ \\
& \left.\quad+X_{\mathrm{B}} X_{\mathrm{C}}\left[L_{\mathrm{BC}}^{(1)}+2 L_{\mathrm{BC}}^{(2)}\left(X_{\mathrm{B}}-X_{\mathrm{C}}\right)+3 L_{\mathrm{BC}}^{(3)}\left(X_{\mathrm{B}}-X_{\mathrm{C}}\right)^{2}\right]\right\}
\end{aligned}
$$

if all three liquid boundary binary systems are described using four polynomial parts $\left(n_{\mathrm{AB}}=n_{\mathrm{AC}}=n_{\mathrm{BC}}=3\right)$ in a power series of their own $G^{\mathrm{E}}$ (see Eqn.(2)). Nevertheless, it is not obligatory to describe the $G^{\mathrm{E}}$ of the binary systems using all four polynomial parts. One or even two or three parts (or $L$ 's) of the total four parts (starting with the highest order) can be zero, depending on the system. However, normally, it is not necessary to use more than four parts in the polynomials to describe $G^{\mathrm{E}}$, but there are a few liquid binary systems that require more parts for the precise description of their $G^{\mathrm{E}}$. Therefore, the equations derived above can almost be considered as general ones.

Since both Eqn. (6) and (15) express the same quantity, i.e., $\left(\partial G^{\mathrm{E}} / \partial X_{\mathrm{A}}\right)_{x}$, the right-hand sides of both equations should also be equal, that is:

$$
\begin{aligned}
& R T \ln \left(\frac{I_{\mathrm{A}} X_{\mathrm{C}}}{I_{\mathrm{C}} X_{\mathrm{A}}}+C_{\mathrm{ABC}\left(\mathrm{A}^{+} / \mathrm{C}^{+}\right)}=-Y_{\mathrm{ABC}\left(\mathrm{A}^{+} / \mathrm{C}^{+}\right)}+L_{\mathrm{ABC}}^{(0)}\left(2 X_{\mathrm{C}}-X_{\mathrm{A}}\right) X_{\mathrm{A}} X_{\mathrm{B}}+\right. \\
& +L_{\mathrm{ABC}}^{(1)}\left(X_{\mathrm{C}}-X_{\mathrm{A}}\right)\left(X_{\mathrm{B}}\right)^{2}+L_{\mathrm{ABC}}^{(2)}\left(X_{\mathrm{C}}-2 X_{\mathrm{A}}\right) X_{\mathrm{C}} X_{\mathrm{B}}
\end{aligned}
$$


Denoting $Y Y_{\mathrm{ABC}\left(\mathrm{A}^{+} / \mathrm{C}^{+}\right)}$and $Y$ summa ${ }_{\mathrm{ABC}\left(\mathrm{A}^{+} / \mathrm{C}^{+}\right)}$as:

$Y Y_{\mathrm{ABC}\left(\mathrm{A}^{+} / \mathrm{C}^{+}\right)} \equiv R T \ln \left(\frac{I_{\mathrm{A}} X_{\mathrm{C}}}{I_{\mathrm{C}} X_{\mathrm{A}}}\right)$

$Y_{\text {summa }}{\operatorname{ABC}\left(\mathrm{A}^{+} / \mathrm{C}^{+}\right)} \equiv Y_{\mathrm{ABC}\left(\mathrm{A}^{+} / \mathrm{C}^{+}\right)}+Y Y_{\mathrm{ABC}\left(\mathrm{A}^{+} / \mathrm{C}^{+}\right)}$

it can be written that

$$
\begin{aligned}
& Y_{\text {summa }} a_{\mathrm{ABC}\left(\mathrm{A}^{+} / \mathrm{C}^{+}\right)}=-C_{\mathrm{ABC}\left(\mathrm{A}^{+} / \mathrm{C}^{+}\right)}+L_{\mathrm{ABC}}^{(0)}\left(2 X_{\mathrm{C}}-X_{\mathrm{A}}\right) X_{\mathrm{A}} X_{\mathrm{B}}+( \\
& +L_{\mathrm{ABC}}^{(1)}\left(X_{\mathrm{C}}-X_{\mathrm{A}}\right)\left(X_{\mathrm{B}}\right)^{2}+L_{\mathrm{ABC}}^{(2)}\left(X_{\mathrm{C}}-2 X_{\mathrm{A}}\right) X_{\mathrm{C}} X_{\mathrm{B}}
\end{aligned}
$$

This method (RKM-KEMS) was applied by us first in Ref. [1]. In a later paper [2], we derived expressions for the use of different ion-intensity ratios (e.g., $\mathrm{Ag}^{+}$to $\mathrm{In}^{+}$or $\mathrm{Ag}^{+}$to $\mathrm{Sn}^{+}$, denoted generally as $A^{+} / B^{+}$or $A^{+} / C^{+}$, respectively) independently for the determination of the theoretically same ternary $L$-parameters and thermodynamic properties by regression. Generalising these expressions to an $A-B-C$ system Eqn. (14) was obtained using not the $A^{+}$to $C^{+}$but the $A^{+}$to $B^{+}$ion-intensity ratio, called the ' $A^{+} / B^{+}$method':

$$
\begin{aligned}
& Y_{\text {summa }} a_{\mathrm{ABC}\left(\mathrm{A}^{+} / \mathrm{B}^{+}\right)}=-C_{\mathrm{ABC}\left(\mathrm{A}^{+} / \mathrm{B}^{+}\right)}+L_{\mathrm{ABC}}^{(0)}\left(2 X_{\mathrm{B}}-X_{\mathrm{A}}\right) X_{\mathrm{A}} X_{\mathrm{B}}+ \\
& +L_{\mathrm{ABC}}^{(1)}\left(X_{\mathrm{B}}-2 X_{\mathrm{A}}\right) X_{\mathrm{C}} X_{\mathrm{B}}+L_{\mathrm{ABC}}^{(2)}\left(X_{\mathrm{B}}-X_{\mathrm{A}}\right)\left(X_{\mathrm{C}}\right)^{2}
\end{aligned}
$$

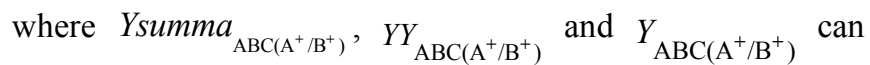
be determined using Eqns. (15), (16) and (17) below:

$$
\begin{aligned}
& Y \text { summa } \\
& { }_{\mathrm{ABC}\left(\mathrm{A}^{+} / \mathrm{B}^{+}\right)} \equiv Y_{\mathrm{ABC}\left(\mathrm{A}^{+} / \mathrm{B}^{+}\right)}+Y Y_{\mathrm{ABC}\left(\mathrm{A}^{+} / \mathrm{B}^{+}\right)} \\
& Y Y_{\mathrm{ABC}\left(\mathrm{A}^{+} / \mathrm{B}^{+}\right)} \equiv R T \ln \left(\frac{I_{\mathrm{A}} X_{\mathrm{B}}}{I_{\mathrm{B}} X_{\mathrm{A}}}\right) \\
& Y_{\mathrm{ABC}\left(\mathrm{A}^{+} / \mathrm{B}^{+}\right)} \equiv \\
& \quad-\left\{X_{\mathrm{B}}\left[L_{\mathrm{AB}}^{(0)}+L_{\mathrm{AB}}^{(1)}\left(X_{\mathrm{A}}-X_{\mathrm{B}}\right)+L_{\mathrm{AB}}^{(2)}\left(X_{\mathrm{A}}-X_{\mathrm{B}}\right)^{2}+L_{\mathrm{AB}}^{(3)}\left(X_{\mathrm{A}}-X_{\mathrm{B}}\right)^{3}\right]+(\right. \\
& \quad+X_{\mathrm{A}} X_{\mathrm{C}}\left[L_{\mathrm{AC}}^{(1)}+2 L_{\mathrm{AC}}^{(2)}\left(X_{\mathrm{A}}-X_{\mathrm{C}}\right)+3 L_{\mathrm{AC}}^{(3)}\left(X_{\mathrm{A}}-X_{\mathrm{C}}\right)^{2}\right]+ \\
& \quad+X_{\mathrm{C}}\left[L_{\mathrm{AC}}^{(0)}+L_{\mathrm{AC}}^{(1)}\left(X_{\mathrm{A}}-X_{\mathrm{C}}\right)+L_{\mathrm{AC}}^{(2)}\left(X_{\mathrm{A}}-X_{\mathrm{C}}\right)^{2}+L_{\mathrm{AC}}^{(3)}\left(X_{\mathrm{A}}-X_{\mathrm{C}}\right)^{3}\right]- \\
& \quad-X_{\mathrm{A}}\left[L_{\mathrm{AB}}^{(0)}+L_{\mathrm{AB}}^{(1)}\left(X_{\mathrm{A}}-X_{\mathrm{B}}\right)+L_{\mathrm{AB}}^{(2)}\left(X_{\mathrm{A}}-X_{\mathrm{B}}\right)^{2}+L_{\mathrm{AB}}^{(3)}\left(X_{\mathrm{A}}-X_{\mathrm{B}}\right)^{3}\right]+ \\
& \quad+X_{\mathrm{A}} X_{\mathrm{B}}\left[2 L_{\mathrm{AB}}^{(1)}+4 L_{\mathrm{AB}}^{(2)}\left(X_{\mathrm{A}}-X_{\mathrm{B}}\right)+6 L_{\mathrm{AB}}^{(3)}\left(X_{\mathrm{A}}-X_{\mathrm{B}}\right)^{2}\right]- \\
& \quad-X_{\mathrm{C}}\left[L_{\mathrm{BC}}^{(0)}+L_{\mathrm{BC}}^{(1)}\left(X_{\mathrm{B}}-X_{\mathrm{C}}\right)+L_{\mathrm{BC}}^{(2)}\left(X_{\mathrm{B}}-X_{\mathrm{C}}\right)^{2}+L_{\mathrm{BC}}^{(3)}\left(X_{\mathrm{B}}-X_{\mathrm{C}}\right)^{3}\right]- \\
& \left.\quad-X_{\mathrm{B}} X_{\mathrm{C}}\left[L_{\mathrm{BC}}^{(1)}+2 L_{\mathrm{BC}}^{(2)}\left(X_{\mathrm{B}}-X_{\mathrm{C}}\right)+3 L_{\mathrm{BC}}^{(3)}\left(X_{\mathrm{B}}-X_{\mathrm{C}}\right)^{2}\right]\right\}
\end{aligned}
$$

Comparing Eqn. (17) with Eqn. (9), certain construction relations become apparent. Eqn. (17) can be obtained from Eqn. (9) by replacing $B$ with $C$ and $C$ with $B$. A similar relationship also exists between Eqns. (13) and (14), but in addition to the exchange of the subscripts $C$ and $B$ in the mole fractions, the multipliers of $L_{\mathrm{ABC}}^{(1)}$ and $L_{\mathrm{ABC}}^{(2)}$ are also exchanged.

It is worth noting that the $L_{\mathrm{ABC}}^{(0)}, L_{\mathrm{ABC}}^{(1)}$ and $L_{\mathrm{ABC}}^{(2)}$ ternary parameters can be obtained from both Eqns. (13) and (14) by multiple regression using different functions. This is the advantage of KEMS, i.e., it is possible to use the whole mass spectrum for the parallel determination of the ternary $L$ 's. The regression matrix-vector equation based on Eqns. (13) and (14) can be expressed by Eqns. (18) and (19) as follows:

$$
\begin{aligned}
& {\left[\begin{array}{cccc}
1 & \left(\left(2 X_{\mathrm{C}}-X_{\mathrm{A}}\right) \cdot X_{\mathrm{A}} X_{\mathrm{B}}\right)_{1} & \left(\left(X_{\mathrm{C}}-X_{\mathrm{A}}\right) \cdot X_{\mathrm{B}}^{2}\right)_{1} & \left(\left(X_{\mathrm{C}}-2 X_{\mathrm{A}}\right) \cdot X_{\mathrm{C}} X_{\mathrm{B}}\right)_{1} \\
1 & \left(\left(2 X_{\mathrm{C}}-X_{\mathrm{A}}\right) \cdot X_{\mathrm{A}} X_{\mathrm{B}}\right)_{2} & \left(\left(X_{\mathrm{C}}-X_{\mathrm{A}}\right) \cdot X_{\mathrm{B}}^{2}\right)_{2} & \left(\left(X_{\mathrm{C}}-2 X_{\mathrm{A}}\right) \cdot X_{\mathrm{C}} X_{\mathrm{B}}\right)_{2} \\
1 & \left(\left(2 X_{\mathrm{C}}-X_{\mathrm{A}}\right) \cdot X_{\mathrm{A}} X_{\mathrm{B}}\right)_{n} & \left(\left(X_{\mathrm{C}}-X_{\mathrm{A}}\right) \cdot X_{\mathrm{B}}^{2}\right)_{n} & \left(\left(X_{\mathrm{C}}-2 X_{\mathrm{A}}\right) \cdot X_{\mathrm{C}} X_{\mathrm{B}}\right)_{n}
\end{array}\right]}
\end{aligned}
$$

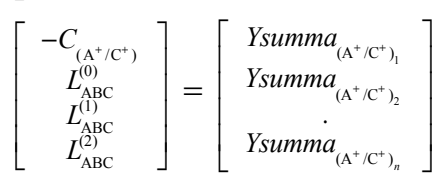

$$
\begin{aligned}
& {\left[\begin{array}{llll}
1 & \left(\left(2 X_{\mathrm{B}}-X_{\mathrm{Al}}\right) \cdot X_{\mathrm{A}} X_{\mathrm{C}}\right)_{1} & \left(\left(X_{\mathrm{B}}-2 X_{\mathrm{A}}\right) \cdot X_{\mathrm{B}} X_{\mathrm{C}}\right)_{1} & \left(\left(X_{\mathrm{B}}-X_{\mathrm{A}}\right) \cdot X_{\mathrm{C}}^{2}\right)_{1} \\
1 & \left(\left(2 X_{\mathrm{B}}-X_{\mathrm{A}}\right) \cdot X_{\mathrm{A}} X_{\mathrm{C}}\right)_{2} & \left(\left(X_{\mathrm{B}}-2 X_{\mathrm{A}}\right) \cdot X_{\mathrm{B}} X_{\mathrm{C}}\right)_{2} & \left(\left(X_{\mathrm{B}}-X_{\mathrm{A}}\right) \cdot X_{\mathrm{C}}^{2}\right)_{2} \\
1 & \left(\left(2 X_{\mathrm{B}}-X_{\mathrm{A}}\right) \cdot X_{\mathrm{A}} X_{\mathrm{C}}\right)_{n} & \left(\left(X_{\mathrm{B}}-2 X_{\mathrm{A}}\right) \cdot X_{\mathrm{B}} X_{\mathrm{C}}\right)_{n} & \left(\left(X_{\mathrm{B}}-X_{\mathrm{A}}\right) \cdot X_{\mathrm{C}}^{2}\right)_{n}
\end{array}\right]} \\
& {\left[\begin{array}{c}
-C_{\left.\mathrm{A}^{+} / \mathrm{B}^{+}\right)} \\
L_{\mathrm{ABC}}^{(0)} \\
L_{\mathrm{ABC}}^{\mathrm{D} D} \\
L_{\mathrm{ABC}}^{\mathrm{ADC}}
\end{array}\right]=\left[\begin{array}{c}
Y_{\text {summa }} \\
\text { Ysumma }_{\left(\mathrm{A}^{+} / \mathrm{B}^{+}\right)_{1}} \\
\left.\dot{\mathrm{A}}^{+} \mathrm{B}^{+}\right)_{2} \\
\text { Ysumma }_{\left(\mathrm{A}^{+} \mathrm{B}^{+}\right)_{n}}
\end{array}\right]}
\end{aligned}
$$

where ' $n$ ' is the number of measured compositions. If $n>4$ the solution of the linear equation system should be replaced with a multiple regression problem. The solution provides the three ternary parameters and the intercept $C$, and, as input parameters, it needs the parameters of the three boundary binary systems (either from own experiments or from the literature) and the measured ion-intensity ratios at various compositions for the given temperature.

In order to decrease the uncertainties of $L_{\mathrm{ABC}}^{(0)}, L_{\mathrm{ABC}}^{(1)}$ and $L_{\mathrm{ABC}}^{(2)}$ determined by the separate $A^{+} / C^{+}$and $A^{+} / B^{+}$methods, Eqns. (13) and (14) can either be added or extracted. Using the addition method, twice the amount of measured input data can be used for a joint multiple regression. The equations of this ' $A^{+} / C^{+}$plus $A^{+} / B^{+}$addition method' are as follows:

$$
\begin{aligned}
& Y_{\text {summa }} \text { added }=-C_{\mathrm{added}}+L_{\mathrm{ABC}}^{(0)}\left(4 X_{\mathrm{A}} X_{\mathrm{B}} X_{\mathrm{C}}-X_{\mathrm{A}}^{2}\left(1-X_{\mathrm{A}}\right)\right)+ \\
& +L_{\mathrm{ABC}}^{(1)}\left(2 X_{\mathrm{B}} X_{\mathrm{C}}-X_{\mathrm{A}} X_{\mathrm{B}}-2 X_{\mathrm{A}} X_{\mathrm{C}}\right) X_{\mathrm{B}}+ \\
& +L_{\mathrm{ABC}}^{(2)}\left(2 X_{\mathrm{B}} X_{\mathrm{C}}-X_{\mathrm{A}} X_{\mathrm{C}}-2 X_{\mathrm{A}} X_{\mathrm{B}}\right) X_{\mathrm{C}}
\end{aligned}
$$

where

$$
\begin{aligned}
& Y_{\text {summa }} a_{\text {added }}=Y \text { summa } \\
& =Y_{\mathrm{ABC}\left(\mathrm{A}^{+} / \mathrm{C}^{+}\right)}+Y_{\mathrm{ABC}\left(\mathrm{A}^{+} / \mathrm{C}^{+}\right)}+Y Y_{\mathrm{ABC}\left(\mathrm{A}^{+} / \mathrm{C}^{+}\right)}+Y_{\mathrm{ABC}\left(\mathrm{A}^{+} / \mathrm{B}^{+}\right)}+Y Y_{\mathrm{ABC}\left(\mathrm{A}^{+} / \mathrm{B}^{+}\right)}= \\
& \left.=Y_{\text {added }}+Y Y_{\text {added }}\right) \\
& C_{\text {added }}=C_{\mathrm{ABC}\left(\mathrm{A}^{+} / \mathrm{C}^{+}\right)}+C_{\mathrm{ABC}(\mathrm{A}+/ \mathrm{B}+)}
\end{aligned}
$$

The only disadvantage of this 'addition method' is that $C_{\text {added, }}$ obtained by multiple regression using Eqn. (20), cannot be apportioned to $C_{\mathrm{ABC}(\mathrm{A}+/ \mathrm{C}+)}$ and $C_{\mathrm{ABC}(\mathrm{A}+/ \mathrm{B}+)}$. This means that the latter two quantities, and hence also the $\sigma_{\mathrm{A}} / \sigma_{\mathrm{C}}$ and $\sigma_{\mathrm{A}} / \sigma_{\mathrm{B}}$ mass spectrometric ionisation cross-section ratios, that are in a mathematical relation with $C_{\mathrm{ABC}(\mathrm{A}+/ \mathrm{C}+)}$ and $C_{\mathrm{ABC}\left(\mathrm{A}+\mathrm{B}^{+}\right)}$according to, for example, Eqn. (7), cannot be separately determined. However, this problem is not a big disadvantage because the main purpose of the multiple regression is to determine the ternary $L$-parameters, and through these quantities, the activities and the excess thermodynamic quantities, rather than to determine mass spectrometric quantities like, for example, the electron 
impact ionisation cross-section ratios. However, the determination of the ionisation cross-section ratios can be useful side-data due to the significant lack of cross-section data in the literature. Nevertheless, we should not forget that the cross-section ratio data obtained from the intercept $(C)$ values correspond only to a single ionising electron energy, i.e., only to a single point in the cross-section vs. electron energy function (ionisation efficiency curve). The applied electron energy range is usually $5-100 \mathrm{eV}$ in mass spectrometry. Therefore, these cross-section data are not a very large addition to the already available literature data. In addition, in most cases, the ion sources of most mass spectrometers provide only the apparent ionisation crosssection ratio data that may differ from the true data to some extent due to the different mass discrimination effects of the mass spectrometer. Therefore, these cross-section ratio data obtained from the intercept $C$ usually correspond only to the local mass spectrometer and, therefore, they are useful data mainly for the local laboratory people if the mass discrimination effects are large. In order to determine the extent of the discrimination, the obtained data should be compared to the existing reliable literature data obtained either with calculations (see [15-18]) or with special equipment [19]. In contrast to the more-or-less large systematic error, the statistical uncertainty of the crosssection ratio data, obtained from intercept $C$, is low due to the multiple regression procedure performed, usually from more than 20 compositions.

Instead of adding Eqns. (13) and (14) it is also possible to extract one from the other. Nevertheless, in this latter case the measured ion intensity of the ion $\mathrm{A}^{+}$is actually not used for the subsequent calculations, since it is omitted from the equation as follows:

$$
\begin{aligned}
& Y Y_{\text {extracted }}=Y Y_{\mathrm{ABC}\left(\mathrm{A}^{+} / \mathrm{C}^{+}\right)}-Y Y_{\mathrm{ABC}\left(\mathrm{A}^{+} / \mathrm{B}^{+}\right)}= \\
& =R T \ln \left(\frac{I_{\mathrm{A}} X_{\mathrm{C}}}{I_{\mathrm{C}} X_{\mathrm{A}}}\right)-R T \ln \left(\frac{I_{\mathrm{A}} X_{\mathrm{B}}}{I_{\mathrm{B}} X_{\mathrm{A}}}\right)=R T \ln \left(\frac{I_{\mathrm{B}} X_{\mathrm{C}}}{I_{\mathrm{C}} X_{\mathrm{B}}}\right)=Y Y_{\mathrm{ABC}\left(\mathrm{B}^{+} / \mathrm{C}^{+}\right)}
\end{aligned}
$$

This 'extraction method' actually leads to the so-called ' $B^{+} / C^{+}$method', since it leads to the elimination of the ionintensity data of $\mathrm{A}^{+}$. Therefore, in contrast to the 'addition method', in the 'extraction method' means that there is no doubling of the input data (i.e., using two kinds of ionintensity ratios) for the multiple regression, but only a single set of input data (i.e., the $B^{+} / C^{+}$ion-intensity ratio data) is used. Obviously, in a ternary system there are only two independent ion-intensity ratios, i.e., the third intensity ratio variant depends on the other two variants. The regression equation for this ' $B^{+} / C^{+}$method' or equivalently the 'extraction method' could be derived as follows:

$$
\begin{aligned}
& Y_{\text {summa }} \text { extracted }=-C_{\text {extracted }}+L_{\mathrm{ABC}}^{(0)} X_{\mathrm{A}}^{2}\left(X_{\mathrm{C}}-X_{\mathrm{B}}\right)+ \\
& +L_{\mathrm{ABC}}^{(1)} X_{\mathrm{A}} X_{\mathrm{B}}\left(2 X_{\mathrm{C}}-X_{\mathrm{B}}\right)+L_{\mathrm{ABC}}^{(2)} X_{\mathrm{A}} X_{\mathrm{C}}\left(X_{\mathrm{C}}-2 X_{\mathrm{B}}\right)
\end{aligned}
$$

where

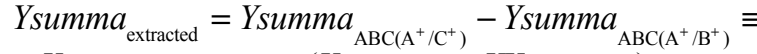

$$
\begin{aligned}
& \equiv Y_{\text {summa }} a_{\mathrm{ABC}\left(\mathrm{B}^{+} / \mathrm{C}^{+}\right)}=\left(Y_{\mathrm{ABC}\left(\mathrm{A}^{+} / \mathrm{C}^{+}\right)}+Y Y_{\mathrm{ABC}\left(\mathrm{A}^{+} / \mathrm{C}^{+}\right)}\right)- \\
& -\left(Y_{\mathrm{ABC}\left(\mathrm{A}^{+} / \mathrm{B}^{+}\right)}+Y Y_{\mathrm{ABC}\left(\mathrm{A}^{+} / \mathrm{B}^{+}\right)}\right)=Y_{\text {extracted }}+Y Y_{\text {extracted }} \equiv \\
& \equiv Y_{\mathrm{ABC}\left(\mathrm{B}^{+} / \mathrm{C}^{+}\right)}+Y Y_{\mathrm{ABC}\left(\mathrm{B}^{+} / \mathrm{C}^{+}\right)}
\end{aligned}
$$

$$
\begin{aligned}
& C_{\text {extracted }}=C_{\mathrm{ABC}\left(\mathrm{A}^{+} / \mathrm{C}^{+}\right)}-C_{\mathrm{ABC}\left(\mathrm{A}^{+} / \mathrm{B}^{+}\right)} \equiv C_{\mathrm{ABC}\left(\mathrm{B}^{+} / \mathrm{C}^{+}\right)} \\
& Y_{\mathrm{ABC(B^{+ } / C ^ { + } )}} \equiv \\
& -X_{\mathrm{A}} X_{\mathrm{C}}\left[L_{\mathrm{AC}}^{(1)}+2 L_{\mathrm{AC}}^{(2)}\left(X_{\mathrm{A}}-X_{\mathrm{C}}\right)+3 L_{\mathrm{AC}}^{(3)}\left(X_{\mathrm{A}}-X_{\mathrm{C}}\right)^{2}\right]- \\
& -X_{\mathrm{A}}^{\mathrm{A}}\left[L_{\mathrm{AB}}^{(0)}+L_{\mathrm{AB}}^{(1)}\left(X_{\mathrm{A}}-X_{\mathrm{B}}\right)+L_{\mathrm{AB}}^{(2)}\left(X_{\mathrm{A}}-X_{\mathrm{B}}^{\mathrm{A}}\right)^{2}+L_{\mathrm{AB}}^{(3)}\left(X_{\mathrm{A}}-X_{\mathrm{B}}\right)^{3}\right]+
\end{aligned}
$$

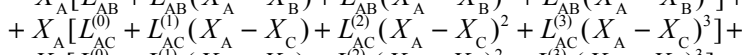

$$
\begin{aligned}
& \left.+X_{\mathrm{B}} \mathrm{B} L_{\mathrm{BC}}^{\mathrm{OCC}}+L_{\mathrm{BC}}^{\mathrm{AC}}\left(X_{\mathrm{B}}-X_{\mathrm{C}}\right)+L_{\mathrm{BC}}^{(2)}\left(X_{\mathrm{B}}-X_{\mathrm{C}}\right)^{2}+L_{\mathrm{BC}}^{(\mathrm{SC})}\left(X_{\mathrm{B}}-X_{\mathrm{C}}\right)^{3}\right]+ \\
& +X_{\mathrm{A}} X_{\mathrm{B}}\left[L_{\mathrm{AB}}^{(1)}+2 L_{\mathrm{AB}}^{(2)}\left(X_{\mathrm{A}}-X_{\mathrm{B}}\right)+3 L_{\mathrm{AB}}^{(3)}\left(X_{\mathrm{A}}-X_{\mathrm{B}}\right)^{2}\right]- \\
& -X_{\mathrm{C}}^{\mathrm{A}}\left[L_{\mathrm{BC}}^{\mathrm{O}(1)}+L_{\mathrm{BC}}^{(1)}\left(X_{\mathrm{B}}-X_{\mathrm{C}}\right)+L_{\mathrm{BC}}^{(2)}\left(X_{\mathrm{B}}-X_{\mathrm{A}}\right)^{2}+L_{\mathrm{BC}}^{(3)}\left(X_{\mathrm{B}}-X_{\mathrm{C}}\right)^{3}\right]- \\
& -X_{\mathrm{B}} X_{\mathrm{C}}\left[2 L_{\mathrm{BC}}^{(1)}+4 L_{\mathrm{BC}}^{(2)}\left(X_{\mathrm{B}}-X_{\mathrm{C}}\right)+6 L_{\mathrm{BC}}^{(3)}\left(X_{\mathrm{B}}-X_{\mathrm{C}}\right)^{2}\right]
\end{aligned}
$$

The corresponding regression matrix-vector equation for the ' $B^{+} / C^{+}$method' on the basis of Eqn. (24) is as follows:

$$
\begin{aligned}
& {\left[\begin{array}{llll}
1 & \left(\left(X_{\mathrm{C}}-X_{\mathrm{B}}\right) \cdot X_{\mathrm{A}}^{2}\right)_{1} & \left(\left(2 X_{\mathrm{C}}-X_{\mathrm{B}}\right) \cdot X_{\mathrm{A}} X_{\mathrm{B}}\right)_{1} & \left(\left(X_{\mathrm{C}}-2 X_{\mathrm{B}}\right) \cdot X_{\mathrm{C}} X_{\mathrm{A}}\right)_{1}
\end{array}\right.} \\
& 1\left(\left(X_{\mathrm{C}}-X_{\mathrm{B}}\right) \cdot X_{\mathrm{A}}^{2}\right)_{2} \quad\left(\left(2 X_{\mathrm{C}}-X_{\mathrm{B}}\right) \cdot X_{\mathrm{A}} X_{\mathrm{B}}\right)_{2} \quad\left(\left(X_{\mathrm{C}}-2 X_{\mathrm{B}}\right) \cdot X_{\mathrm{C}} X_{\mathrm{A}}\right)_{2} \\
& \left.i\left(\left(X_{\mathrm{C}}-X_{\mathrm{B}}\right) \cdot X_{\mathrm{A}}^{2}\right)_{n}\left(\left(2 X_{\mathrm{C}}-X_{\mathrm{B}}\right) \cdot X_{\mathrm{A}} X_{\mathrm{B}}\right)_{n}\left(\left(X_{\mathrm{C}}-2 X_{\mathrm{B}}\right) \cdot X_{\mathrm{C}} X_{\mathrm{A}}\right)_{n}\right] \\
& {\left[\begin{array}{c}
-C_{\left(\mathrm{B}^{+} / \mathrm{C}^{+}\right)} \\
L_{\mathrm{ABC}}^{(0)} \\
L_{\mathrm{ABC}}^{1 \mathrm{BC}} \\
L_{\mathrm{ABC}}^{(2)}
\end{array}\right]=\left[\begin{array}{c}
Y_{\text {summa }} \\
\text { Ysumma }_{\left(\mathrm{B}^{+} / \mathrm{C}^{+}\right)_{1}} \\
{\dot{\left(\mathrm{B}^{+} / \mathrm{C}^{+}\right)_{2}}}_{\text {Ysumma }_{\left(\mathrm{B}^{+} / \mathrm{C}^{+}\right)_{n}}}
\end{array}\right]}
\end{aligned}
$$

Theoretically, all the fitting methods $-{ }^{+} A^{+} / B^{\prime},{ }^{\prime} A^{+} / C^{\prime}$, ' $B^{+} / C$ ' and the two variations of the addition method should provide the same ternary $L$-parameters. The reason for the deviation between the $L$-data obtained from the above-mentioned regression methods, on the one hand, is the different accuracy of the ion-intensity data of the components, and, on the other hand, a possible non-validity of the applied model, since obviously the above-mentioned relations between the various methods are valid only in the case of the validity of the applied RKM model.

Using the ternary $L$ 's obtained from any of the Eqns. (13), (14), (20) or (24) it is possible to obtain the excess Gibbs energy based on Eqn. (2). From the latter equation it is possible to determine the excess chemical potentials, the activity coefficients and the activities analytically using the following well-known thermodynamic relationships (29), (30), (31) and (32):

$$
\begin{aligned}
& a_{\mathrm{i}}=X_{\mathrm{i}} \gamma_{\mathrm{i}}=X_{\mathrm{i}} \exp \left(\frac{\mu_{\mathrm{i}}^{\mathrm{E}}}{\mathrm{R} T}\right) \\
& \mu_{\mathrm{A}}^{\mathrm{E}}=G^{\mathrm{E}}-X_{\mathrm{B}}\left(\frac{\partial \mathrm{G}^{\mathrm{E}}}{\partial X_{\mathrm{B}}}\right)_{X_{\mathrm{C}}}-X_{\mathrm{c}}\left(\frac{\partial \mathrm{G}^{\mathrm{E}}}{\partial X_{\mathrm{C}}}\right)_{X_{\mathrm{B}}}=G^{\mathrm{E}}-X_{\mathrm{B}}\left(\frac{\partial \mathrm{G}^{\mathrm{E}}}{\partial X_{\mathrm{B}}}\right)_{X_{\mathrm{A}}}+\left(1-X_{\mathrm{A}}\right)\left(\frac{\partial \mathrm{G}^{\mathrm{E}}}{\partial X_{\mathrm{A}}}\right)_{X_{\mathrm{B}}} \\
& \mu_{\mathrm{C}}^{\mathrm{E}}=G^{\mathrm{E}}-X_{\mathrm{A}}\left(\frac{\partial \mathrm{G}^{\mathrm{E}}}{\partial X_{\mathrm{A}}}\right)_{X_{\mathrm{B}}}-X_{\mathrm{B}}\left(\frac{\partial \mathrm{G}^{\mathrm{E}}}{\partial X_{\mathrm{B}}}\right)_{X_{A}} \\
& \mu_{\mathrm{B}}^{\mathrm{E}}=G^{\mathrm{E}}-X_{\mathrm{A}}\left(\frac{\partial \mathrm{G}^{\mathrm{E}}}{\partial X_{\mathrm{A}}}\right)_{X_{\mathrm{C}}}-X_{\mathrm{C}}\left(\frac{\partial \mathrm{G}^{\mathrm{E}}}{\partial X_{\mathrm{C}}}\right)_{X_{A}}
\end{aligned}
$$

where $i$ denotes any of the components $(A, B$ or $C)$. According to Eqns. (30-32), in order to determine all three excess chemical potentials or activities, the determination of four derivatives is sufficient instead of determining the total of six, since only four derivatives are independent. The mathematical relation for the derivatives is shown by Eqn. (30). In addition to the excess chemical potentials and activities, it is also possible to obtain the partial-molar and integral-molar excess enthalpies and entropies from the 
temperature dependence of the excess chemical potentials or activities using the well-known Gibbs-Helmholtz equation.

\section{Conventional KEMS Methods}

A good summary about the determination of component activities for a mixture by KEMS can be found in several literature sources, e.g., [20, 21]. In general, there are six main KEMS methods that provide the activities, either through the determination of vapour pressures or directly. These methods are as follows:

1. The simple pressure calibration method (SPC), involves pure substances as reference substances, having well-known vapour pressures, which are measured in an experiment that takes place before and/or after the mixture experiment. If possible, the pure components of the mixture should be chosen as the pure substances for the calibration procedure. In this way, the instrument sensitivity is determined (in practice), if no multiple cell, but only a single Knudsen cell, is available. The uncertainty of the vapour pressures or activities determined in this way can reach as high as the maximum $\pm 20 \%$ due to the natural fluctuation of the sensitivity constant on a day--to-day basis.

2. The internal standard method (ISM) applies a suitable internal standard substance that is loaded into the same single cell together with the studied sample. Only those substances that do not react and/or mix with the sample and/or the cell material and with volatilities that are high enough to be detected by the mass spectrometer are suitable as internal standards.

3. The twin or multiple Knudsen cell technique (MKC). Some of the compartments of a multiple cell are filled with the pure components, the others with different compositions of the mixture.

4. The oligomer composition change (OCC) method. This method can only be applied in the case that one of the components vaporises in the form of oligomers, such as, e.g., $\mathrm{Sb}(\mathrm{g}), \mathrm{Sb}_{2}(\mathrm{~g}), \mathrm{Sb}_{3}(\mathrm{~g}), \mathrm{Sb}_{4}(\mathrm{~g})$ in the equilibrium vapour over $\mathrm{Sb}(\mathrm{s})$. The composition of the oligomers changes with mixing, i.e., by reducing its activity.

5. The mass spectrometric Gibbs-Duhem Ion Intensity Ratio Method (GD-IIRM) that is a modification of the wellknown Gibbs-Duhem relationship using MS quantities (i.e., ion-intensity ratios).

6. The mass spectrometric isothermal evaporation ('mass loss') method (IEM-KEMS). A part of the sample is evaporated at a constant temperature for certain duration and in addition to the measurement of the temperature, duration and evaporated mass, the mass spectrum is also recorded.

In our KEMS experiments in connection with the studied liquid ternary alloys, in addition to the RKM-KEMS method, four conventional methods, i.e., methods 1, 4, 5 and 6, were applied. In Method 6 the conventional Knudsen effusion isothermal evaporation method (IEM), that does not require a mass spectrometer, is supplemented with mass spectrometry (IEM-KEMS) [11, 20]. The latter procedure (IEM-KEMS) involves not only the determination of the total evaporation ('total mass loss') rate but also the determination of the ion intensities generated from the equilibrium vapour over the condensed mixture at constant temperature. This method provides not only the total pressure, but also the partial vapour pressures and the activities as well and providing these data without assuming any mixture-model. Therefore, it is worth applying the IEMKEMS to confirm the partly model-dependent RKM-KEMS data. Thus, since IEM-KEMS provides pure experimental data, it also serves as a reference for the RKM-KEMS data. An alternative possibility for determining the equilibrium partial pressures is, instead of obtaining the mass spectrum, to analyse the deposit (IEM-VDA) of the vapour beam by conventional analytical chemical methods. Popovič [12] was the first researcher to develop this technique using a Knudsen effusion mass spectrometer for the determination of the equilibrium partial pressures and ionisation crosssections by combing the IEM-VDA and the IEM-KEMS methods, creating in this way the so-called IEM-VDAKEMS method. Combining IEM-VDA with IEM-KEMS means that it is possible to determine not only the equilibrium partial pressures of the gas-phase components but also the relative ionisation cross-sections of the gasphase molecules in the same equilibrium vapour. The simple IEM-VDA method needs only a Knudsen evaporator in a high-vacuum system, but it does not require a mass spectrometer. Nevertheless, we performed both the IEMVDA and the IEM-KEMS experiments in parallel in the same KEMS apparatus in order to determine not only the equilibrium vapour pressures, but also the relative ionisation cross-sections as well. In our KEMS apparatus the technical realisation of this method was through the use of some sticky-tape fixed onto the water-cooled inner wall of the mass spectrometer's central flange. The tape was just facing the molecular beam coming from the equilibrium vapour mixture. The mixed vapour of the alloy, crossing the ionisation chamber, condensed on the cold tape, forming a thin film of metal mixture. The sticky-tape did not contaminate and destroy the vacuum at all. The deposited thin film was then dissolved off the tape using appropriate acids and the metal composition of the solution was analysed using inductively coupled plasma atomic emission spectroscopy (ICP-AOS). An alternative method for analysing the mixed metal film was a neutron activation analysis (NAA), which has the advantage of not damaging and corroding the film. Therefore, first NAA, and then, as a confirmatory method, ICP-AOS was applied. By applying both methods, the uncertainties in the concentration data could be reduced.

The mass loss is due to the long-term isothermal evaporation from the Knudsen cell - the vapours leave the cell through the orifice, causing a reduction of the sample's mass. If the mass spectrum (the ion intensities of all the components) is also measured simultaneously (IEM-KEMS) and we assume a negligible compositional shift, the partial pressures can be determined using Eqn. (1) and the also well-known Hertz-Knudsen equation, as follows:

$$
\begin{aligned}
& p_{\mathrm{A}}=\frac{K \cdot T}{\sigma_{\mathrm{A}} \cdot \eta_{\mathrm{A}^{+}} \cdot \gamma_{\mathrm{A}^{+}}} I_{\mathrm{A}^{+}} \quad p_{\mathrm{B}}=\frac{K \cdot T}{\sigma_{\mathrm{B}} \cdot \eta_{\mathrm{B}^{+}} \cdot \gamma_{\mathrm{B}^{+}}} I_{\mathrm{B}^{+}} \\
& p_{\mathrm{C}}=\frac{K \cdot T}{\sigma_{\mathrm{C}} \cdot \eta_{\mathrm{C}^{+}} \cdot \gamma_{\mathrm{C}^{+}}} I_{\mathrm{C}^{+}}
\end{aligned}
$$


where the sensitivity constant, $K$, is:

$K=\sqrt{\frac{2 \pi \mathrm{R}}{T}} \frac{\Delta m}{\bar{C} \bar{A} \Delta t}\left(\frac{I_{\mathrm{A}^{+}}}{\sigma_{\mathrm{A}} \eta_{\mathrm{A}^{+}} \gamma_{\mathrm{A}^{+}}} \sqrt{M_{\mathrm{A}^{+}}}+\frac{I_{\mathrm{B}^{+}}}{\sigma_{\mathrm{B}} \eta_{\mathrm{B}^{+}} \gamma_{\mathrm{B}^{+}}} \sqrt{M_{\mathrm{B}}}+\frac{I_{\mathrm{C}^{+}}}{\sigma_{\mathrm{C}} \eta_{\mathrm{C}^{+}} \gamma_{\mathrm{C}^{+}}} \sqrt{M_{\mathrm{C}}}\right)^{-1}$

where $\Delta m$ is the total mass loss, $\Delta t$ is the duration of the isothermal evaporation experiment, $K$ is the sensitivity constant of the mass spectrometer, $M$ is the molar mass of an effusing gaseous species, $A$ is the area of the orifice of the Knudsen cell, $C$ is the Clausing factor of the orifice, and $R$ is the universal gas constant. The term $M$ denotes the mean molar mass if the effusing species are not mono-isotopic, whereas the ion intensity $(I)$ and the detector (multiplier) gain factor $(\gamma)$ belong to the measured (selected) isotopic ion. A correction of the selected isotopic ion intensity to the total ion intensity is performed using the isotopic abundance factor $(\eta)$. Note that using this technique the cross-section data $(\sigma)$ must be taken from elsewhere as the input data (e.g., from the literature), i.e., they are not determined using this experiment.

The total mass loss of the sample, which can simply be measured using an analytical balance before and after the isothermal evaporation experiment, consists of the partial mass losses of the components. If we combine the measurement of the total mass loss with the chemical analysis of the vapour deposit rather than with the determination of the mass spectrum, the equations of the IEM-VDA method for determining the equilibrium partial pressures can be obtained as follows:

$\Delta m=\Delta m_{\mathrm{A}}+\Delta m_{\mathrm{B}}+\Delta m_{\mathrm{C}}$

$p_{\mathrm{A}}=\frac{\Delta m_{\mathrm{A}}}{\bar{C} \bar{A} \Delta t} \sqrt{\frac{2 \pi \mathrm{R} T}{M_{\mathrm{A}}}}$

$p_{\mathrm{B}}=\frac{\Delta m_{\mathrm{B}}}{\bar{C} \bar{A} \Delta t} \sqrt{\frac{2 \pi \mathrm{R} T}{M_{\mathrm{B}}}} \quad p_{\mathrm{C}}=\frac{\Delta m_{\mathrm{C}}}{\bar{C} \bar{A} \Delta t} \sqrt{\frac{2 \pi \mathrm{R} T}{M_{\mathrm{C}}}}$

The thermodynamic activities can be obtained from the pressures using the well-known thermodynamic formulae as follows:

$a_{\mathrm{A}}=\frac{p_{\mathrm{A}}}{p_{\mathrm{A}}^{*}}$ and $a_{\mathrm{B}}=\frac{p_{\mathrm{B}}}{p_{\mathrm{B}}^{*}}$ and $a_{\mathrm{C}}=\frac{p_{\mathrm{C}}}{p_{\mathrm{C}}^{*}}$

where $\Delta m_{\mathrm{A}}, \Delta m_{\mathrm{B}}$ and $\Delta m_{\mathrm{C}}$ are the partial mass losses of the alloy components $A, B$ and $C$, respectively, and obtained from the total mass loss and the elementary analysis of the vapour deposit. $p_{\mathrm{A}}^{*}, p_{\mathrm{B}}^{*}$ and $p_{\mathrm{C}}^{*}$, are the vapour pressures of pure $A, B$ and $C$, respectively, and can be obtained either from the literature or by performing our own measurements as follows.

If the evaporation experiments with pure components are also performed at the same temperature and using the same Knudsen cell as that used for the alloy samples, it is not necessary to determine the Clausing factor of the orifice $(C)$ and the orifice area $(A)$ since these parameters are omitted from the formula by applying Eqn. (35) for both the pure metal and the alloy:
$a_{\mathrm{Me}}=\frac{p_{\mathrm{Me}}}{p_{\mathrm{Me}}^{*}}=\frac{\left(d m_{\mathrm{Me}} / d t\right)}{\left(d m_{\mathrm{Me}} / d t\right)^{*}} \approx \frac{\left(\Delta m_{\mathrm{Me}} / \Delta t\right)}{\left(\Delta m_{\mathrm{Me}} / \Delta t\right)^{*}}$

where Me denotes either $A, B$ or $C$ and the asterisk (*) denotes the pure component.

Using this IEM-VDA method it is possible to also avoid the use of literature ionisation cross-sections in order to decrease the systematic error in the thermodynamic data. We performed isothermal evaporation experiments on the $\mathrm{Al}-\mathrm{Cu}$ Sn system [3] at $1453 \mathrm{~K}\left(1180{ }^{\circ} \mathrm{C}\right)$. The above-mentioned equations are only valid in the case when no significant compositional shift or distillation occurs during the IEMVDA-KEMS experiments. To decrease the effect of the distillation of the sample either the duration of the evaporation should be reduced to a reasonably small value or the initial total mass should be increased to the maximum value. In order to decrease the effect of the distillation we applied both of these methods. The similar volatility of the pure components and an optimal composition may also help to reduce the distillation, but these latter conditions can be achieved in very few cases. Note that our aim was to determine the activities in various compositions rather than studying only one 'optimal' composition. If the volatility of a component is much higher (i.e., orders of magnitude) than that of the other components, this method does not require the measurement of the mass spectrum and the analysis of the vapour deposit (see Refs. [1], [2] and [4]) if only the activity of the volatile component is required. Nevertheless, if the volatility of one of the components is much higher than that of the others, shorter evaporation times should be applied in order to avoid a rapid distillation. This is not the case for the Al-Cu-Sn system [3], since the volatilities of the components are comparable. However, in the $\mathrm{Cu}-\mathrm{Sb}-\mathrm{Sn}$ system [4] the volatility of $\mathrm{Sb}$ is much larger than that of the other two components. In the case of the $\mathrm{Cu}-\mathrm{In}-\mathrm{Sn}[1]$ and Ag-In-Sn [2] alloys, the volatility of In is also much higher than that of the other two components. In our experiments a typical mass loss from a starting $1000 \mathrm{mg}$ of sample was 10 $\mathrm{mg}$. Therefore, we required practically no compositional correction for any system studied. IEM-VDA-KEMS was only used to compare the activity data with those provided by the RKM model, since mass-loss measurements are relatively time consuming. A further disadvantage of the IEM methods is that the data obtained from a single evaporation experiment belong only to that particular composition studied and to the particular temperature of the isothermal evaporation. Therefore, we can get thermodynamic data only for one point in the isothermal section of the ternary phase diagram.

In addition to using the IEM-VDA technique to determine the vapour pressures over the alloys, this technique was used by to determine the vapour pressure of pure liquid $\mathrm{Al}$ as well, since there is a large discrepancy in the literature concerning the vapour pressure of this element [3]. This is likely to be due to the creeping process of the molten $\mathrm{Al}$ through the orifice, which contributes to the mass loss caused by the vaporisation. Thus the apparent 'vapour pressure' obtained from the total mass loss is false, i.e., it is higher than the true value. In certain systems the surface tension of the liquid sample on the applied cell material is so 
low that not only the vapour but also, to some extent, the liquid sample flows out through the orifice. This creeping phenomenon may be unobservable to the naked eye, but it is noticeable from the enhanced mass loss and from the broader shutter profile. We also experienced this creeping phenomenon for pure liquid $\mathrm{Al}$ from the alumina cell, and to a smaller extent for pure liquid $\mathrm{Cu}$ from the same cell. This undesirable phenomenon can be reduced or restricted in the following ways: $a$ ) using an alternative cell material that is either more porous or moisturised by the liquid sample with a lower efficiency, $b$ ) using the same cell material but in a much more porous form to create a larger inner surface area, c) using an inner liner (cup), as a sample holder, made of porous or less wetable material or $d$ ) using a channel-type orifice having a lower Clausing factor and a larger interior surface area. Despite this, instead of choosing most of the above-listed solutions ( $a, b$ and $d$ ) and during a trial-anderror experiment, in addition to method $\mathrm{c}$, we decided to determine the vapour pressure over pure liquid Al using the vapour-deposition method. The essence of this solution is that only the mass loss and not the vapour pressure is affected by creeping. We deposited the vapours over pure liquid $\mathrm{Al}$ and, in a subsequent experiment, over pure liquid $\mathrm{Sn}$ on the same piece of sticky-tape over the same time interval and using the same cell. The layered-deposit film of $\mathrm{Al}$ and $\mathrm{Sn}$ was then dissolved in acid and the concentration ratio of $\mathrm{Al}$ to $\mathrm{Sn}$ determined by ICP-AOS. We chose pure $\mathrm{Sn}$ as a reference substance since liquid $\mathrm{Sn}$ does not creep from the alumina cell, and therefore, we considered the literature vapour pressure of $\mathrm{Sn}$ to be reliable. The vapour pressure of Al was determined using Eqn. (38), which is derived from Eqn. (35):

$\frac{p_{\mathrm{Al}}}{p_{\mathrm{Sn}}}=\frac{m_{\mathrm{Al}}}{m_{\mathrm{Sn}}} \sqrt{\frac{M_{\mathrm{Sn}}}{M_{\mathrm{Al}}}}$

where $m_{\mathrm{Al}}$ and $m_{\mathrm{Sn}}$ denote the masses of $\mathrm{Al}$ and $\mathrm{Sn}$ in the layered-deposit film, respectively. The results obtained by applying this method confirmed that the literature vapourpressure data on pure liquid Al are slightly high, probably due to creeping [3].

The third method (method 5), which is also a conventional KEMS technique and used to determine the activities of the components $A, B$ and $C$, is the so-called Gibbs-Duhem ion-intensity ratio (GD-IIR) method, introduced by Belton and Fruehan, first for binary [13] and then later also for ternary systems [22]. This method is also used for comparison purposes since the calculations are made only for the measured compositions (without interpolation). A recent study of Bencze et al., who applied this method to the ternary solid Al-Fe-Ni system, is found in Ref. [23]. The activity coefficients of the components in the $A-B-C$ system, using the GD-IIR method, can be expressed by Eqns. (39), (40) and (41) as follows:

$$
\begin{aligned}
& \ln \gamma_{\mathrm{A}}(X)=\ln \gamma_{\mathrm{A}}\left(X_{\mathrm{ref}}\right)-\int_{X_{\mathrm{ref}}}^{X} X_{\mathrm{B}} d \ln \left(\frac{I_{\mathrm{B}}^{+} X_{\mathrm{A}}}{I_{\mathrm{A}}^{+} X_{\mathrm{B}}}\right)-\int_{X_{\mathrm{ref}}}^{X} X_{\mathrm{C}} d \ln \left(\frac{I_{\mathrm{C}}^{+} X_{\mathrm{A}}}{I_{\mathrm{A}}^{+} X_{\mathrm{C}}}\right) \\
& \ln \gamma_{\mathrm{B}}(X)=\ln \gamma_{\mathrm{B}}\left(X_{\text {ref }}\right)-\int_{X_{\text {ref }}}^{X} X_{\mathrm{A}} \mathrm{d} \ln \left(\frac{I_{\mathrm{A}}^{+} X_{\mathrm{B}}}{I_{\mathrm{B}}^{+} X_{\mathrm{A}}}\right)-\int_{X_{\text {ref }}}^{X} X_{\mathrm{C}} \mathrm{d} \ln \left(\frac{I_{\mathrm{C}}^{+} X_{\mathrm{B}}}{I_{\mathrm{B}}^{+} X_{\mathrm{C}}}\right)
\end{aligned}
$$

$\ln \gamma_{\mathrm{C}}(X)=\ln \gamma_{\mathrm{C}}\left(X_{\text {ref }}\right)-\int_{X_{\text {ref }}}^{X} X_{\mathrm{B}} \mathrm{d} \ln \left(\frac{I_{\mathrm{B}}^{+} X_{\mathrm{C}}}{I_{\mathrm{C}}^{+} X_{\mathrm{B}}}\right)-\int_{X_{\text {ref }}}^{X} X_{\mathrm{A}} \mathrm{d} \ln \left(\frac{I_{\mathrm{A}}^{+} X_{\mathrm{C}}}{I_{\mathrm{C}}^{+} X_{\mathrm{A}}}\right)$

where $X_{\text {ref }}$ denotes the mole fraction of the reference alloy at which the Gibbs-Duhem integration starts. It can be seen from Eqns. (39-41) that this method does not require a determination of vapour pressures, i.e., the activities are determined directly.

During the study of the $\mathrm{Cu}-\mathrm{Sb}-\mathrm{Sn}$ system [4] only $\mathrm{Sb}^{+}$ ions could be detected due to the very large volatility difference between the $\mathrm{Sb}$ and the other components. Therefore, for the evaluation of Sb activity Methods 1 and 4 were applied due to the lack of any ion-intensity ratio data. The obtained Sb activity data were fitted directly to Eqn. (2) in order to evaluate the three ternary $L$-parameters. Knowing the latter quantities the activities of the other components could also be obtained by means of Eqns. (29-32).

\section{APPLICATION AND DISCUSSION}

If the set of measurements is not continuous, i.e., there is a long break in the measurement series or there is a sudden change in the condition of the ion source or detector system (e.g., a multiplier) during the measurement series, the measurements after the break or the sudden change will not be compatible with those carried out before. A sudden change in the condition of the ion source or multiplier system can be caused by, for example,

i) a cathode-filament exchange causing a slightly different filament position relative to the ionisation chamber, and hence, a slightly different position of the electron trajectories inside the ionisation chamber. As a consequence, the mass spectrum can also be slightly different,

ii) a sudden drop or a continuous decrease in the efficiency of the multiplier, etc.

In addition, there can also be a slow, continuous, not very noticeable change as well by, for example, the formation of a dielectric layer on the ion source lenses by the deposition of vapours. All of these above-mentioned effects might cause a small or large continuous or sudden change in the mass spectrum. Some of these reasons, like the partial deposition of the vapour beam or that of condensable background vapour, can be totally (or almost totally) avoided with proper arrangements. Nevertheless, some effects, like, e.g., a sudden random defect or continuous fatigue of the multiplier or a filament exchange caused by the burning of an old cathode filament cannot be avoided. If not all the individual measurements are compatible with each other due to the above-mentioned or other reasons, the set of measurements should be apportioned to a different measurement series to eliminate the shift in the mass spectrum, if it is possible at all. Otherwise, the systematic errors of the obtained thermodynamic quantities could be larger due to this shift. Certainly, all the measurement series should provide the same thermodynamic properties, in principle in as much as the intensity ratios are used, but the obtained data, due to the different accuracies of the individual measurements, are usually different. In addition, to decrease the uncertainties of the ternary $L$-data obtained by the regression procedure, all the series should include the investigation of at least 20-25 compositions. When the total set of the individual 
Table 1. Ternary $L$-parameters of Al-Cu-Sn system [3] obtained by the multi-linear regression at five or seven selected temperatures using the binary $L$-databases from Refs. [24] and [25] and using the $\mathrm{Cu}^{+} / \mathrm{Sn}^{+}$ion-intensity ratios measured in this work for Run 1, Run 2 and also for the merged run. $A, B$ and $C$ are parameters of the $L(T)=\mathrm{A}+B T+C T \ln (T)$ functions. The data are compared to those of Ref. [26]

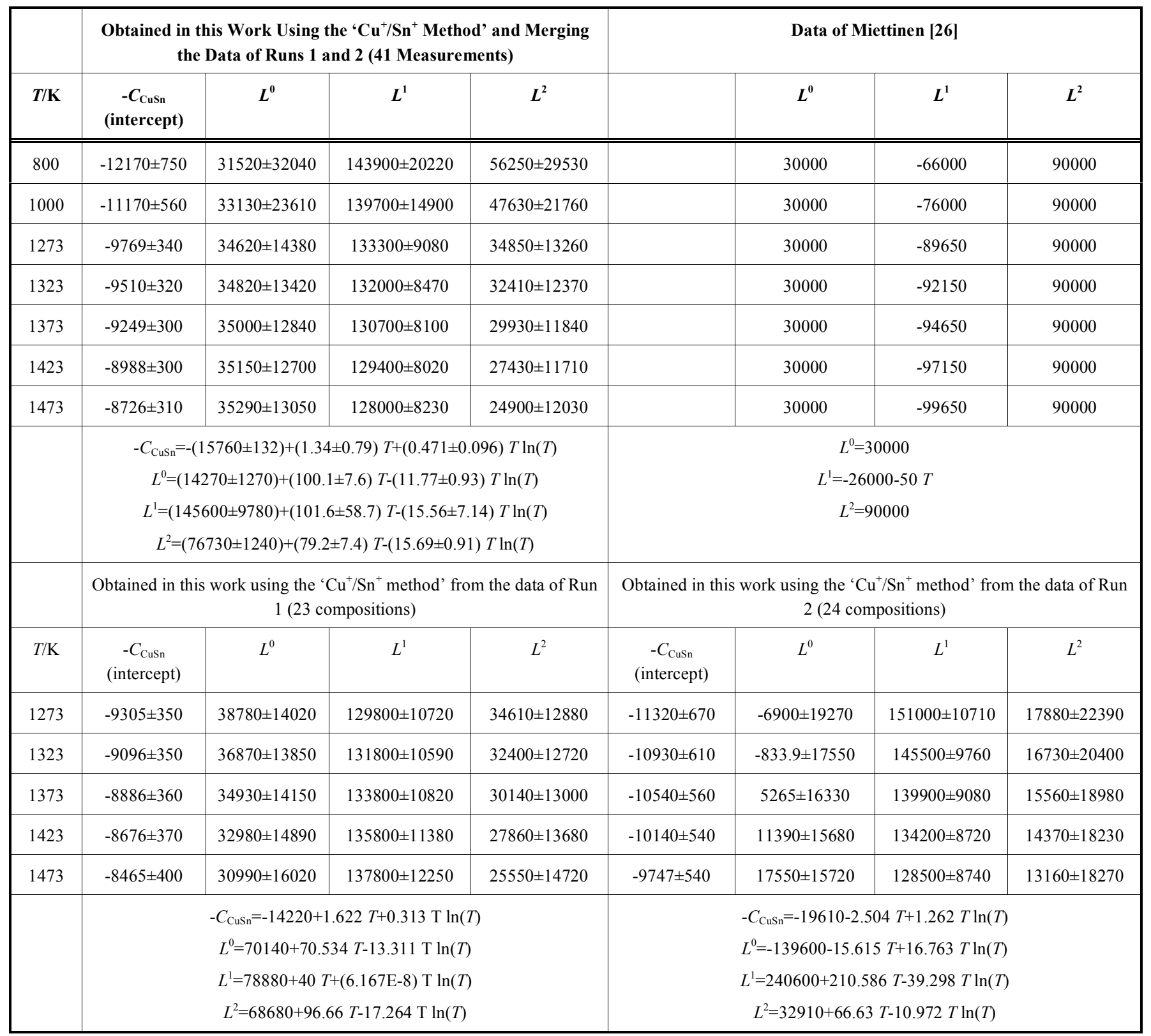

The numbers behind the \pm represent standard deviations.

measurements had to be apportioned to two or more series (see Refs. [2, 3]) we calculated the data from each series separately. Nevertheless, if the mass spectrum is not shifted significantly (like during the study of the Al-Cu-Sn system [3]) we tried to do the regression even with the merged series (total set) since by increasing the number of the input datapoints (compositions) the uncertainties of the calculated values must decrease. During the study of the Al-Cu-Sn system [3], in addition to the separate regressions on the different measurement series, a regression was applied on the merged series, which during the 3-month-long break in the investigations did not shift the mass spectrum significantly in spite of the fact that the instrument was used for the investigation of another system during this break.
Table 1 and Fig. (1) show this effect on the example of the ternary $L$-parameters and the ternary interaction parts of $G^{\mathrm{E}}$ for the Al-Cu-Sn system [3], respectively. The binary databases used for the calculations were taken from Refs. $[24,25]$ and our own data were compared to those of Miettinen [26].

Another decision should be made about whether to apply all the three ion-intensity ratio methods (' $A^{+} / C^{+}$method', ' $A^{+} / B^{+}$method' or ' $B^{+} / C^{+}$method') or to select one of them for evaluating the data. During the investigation of the $\mathrm{Cu}$ In-Sn system [1] only the ' $\mathrm{Cu}^{+} / \mathrm{Sn}^{+}$method' was applied, whereas both the ' $\mathrm{Ag}^{+} / \mathrm{Sn}^{+}$' and ' $\mathrm{Ag} \mathrm{g}^{+} / \mathrm{In}^{+}$' methods were applied during the investigation of the Ag-In-Sn system [2]. 

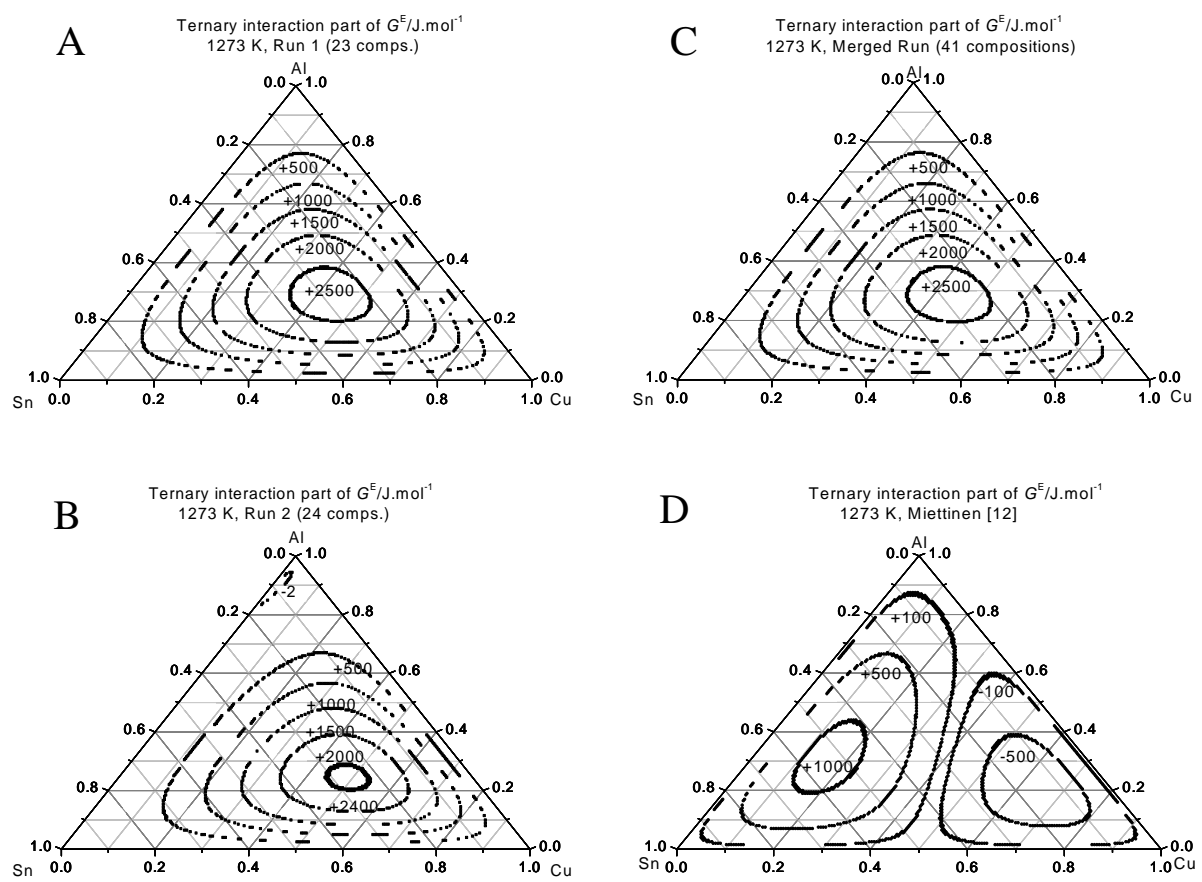

Fig. (1). The iso-curves of the ternary interaction part of the excess Gibbs energy in Al-Cu-Sn [3] at $1273 \mathrm{~K}$, obtained from Run 1 ( $A$ ), Run 2 $(B)$ and the merged run $(C)$ using the ' $\mathrm{Cu}^{+} / \mathrm{Sn}^{+}$method', and from Miettinen' s [26] data $(D)$, using literature binary $L$-parameters from $[24$, $25]$.
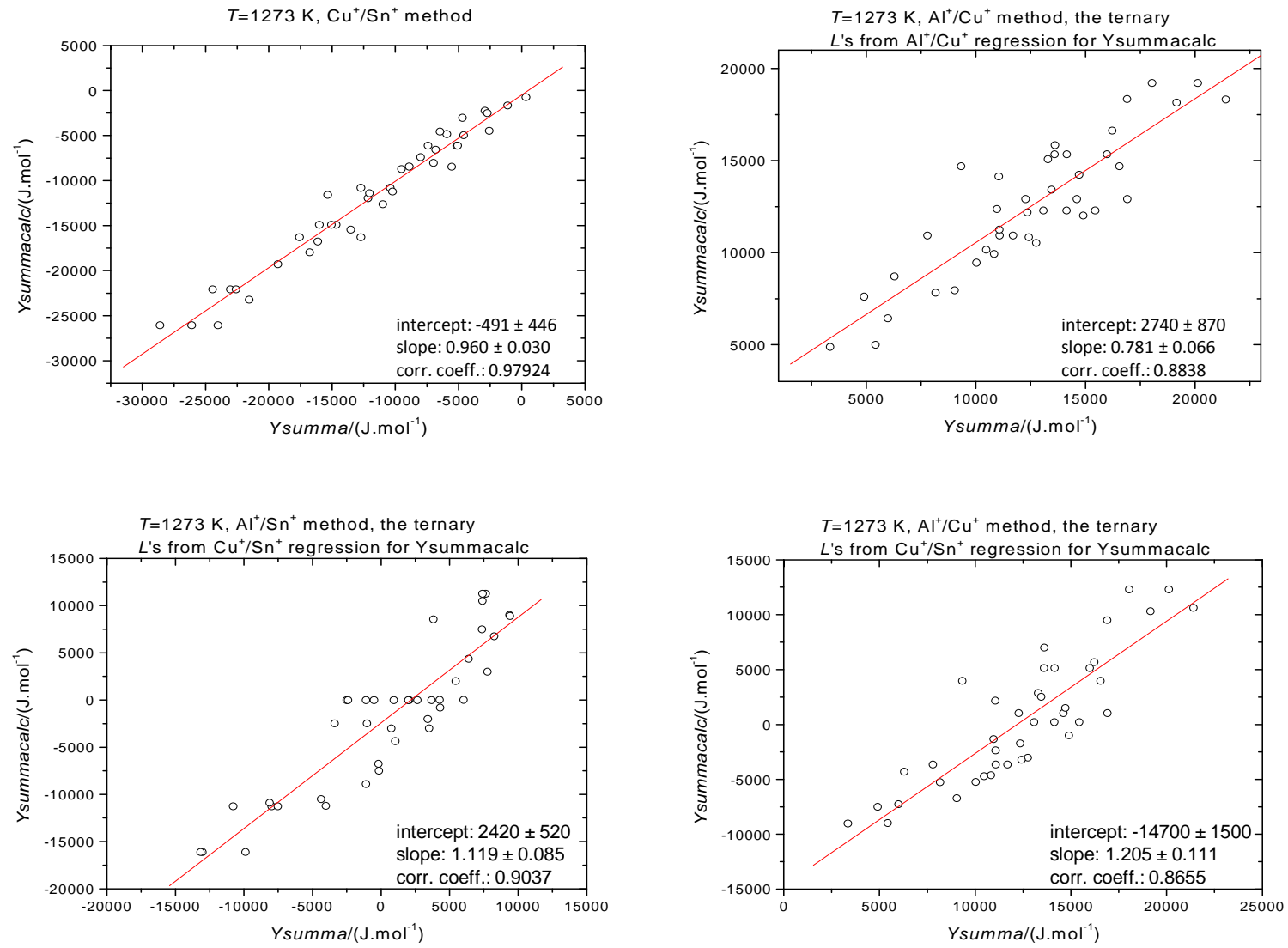

Fig. (2). Ysummacalc as a function of Ysumma using all the 41 measurements (merged data of Run 1 and Run 2) in Al-Cu-Sn [3] and using all the three ion-intensity ratio methods (' $\mathrm{Al}^{+} / \mathrm{Sn}^{+}, \mathrm{Al}^{+} / \mathrm{Cu}^{+}$and $\mathrm{Cu}^{+} / \mathrm{Sn}^{+}$methods') at $1273 \mathrm{~K}$. 


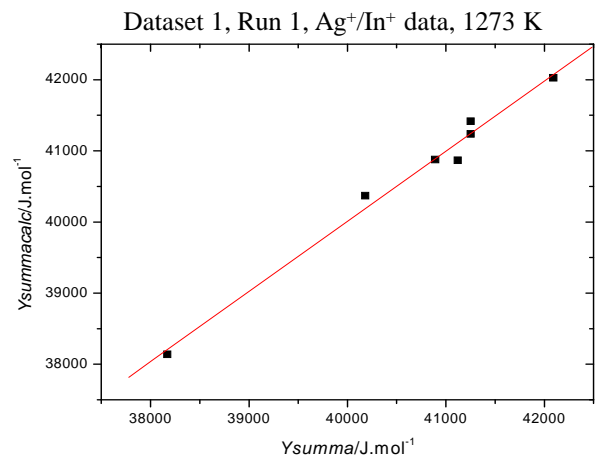

Dataset 2, Run 3, $\mathrm{Ag}^{+} / \mathrm{Sn}^{+}$data, $1273 \mathrm{~K}$

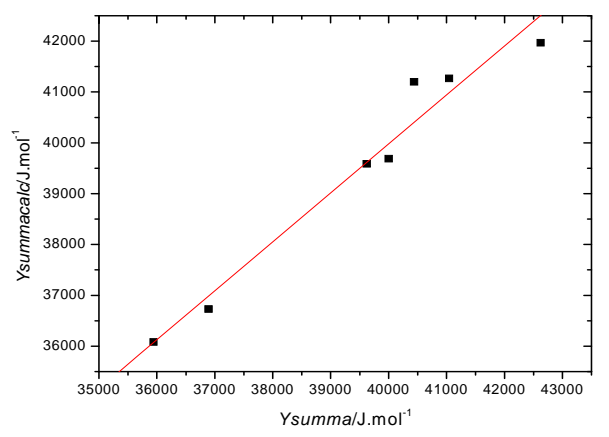

Dataset 1, Run 2, $\mathrm{Ag}^{+} / \mathrm{In}^{+}$data, $1273 \mathrm{~K}$

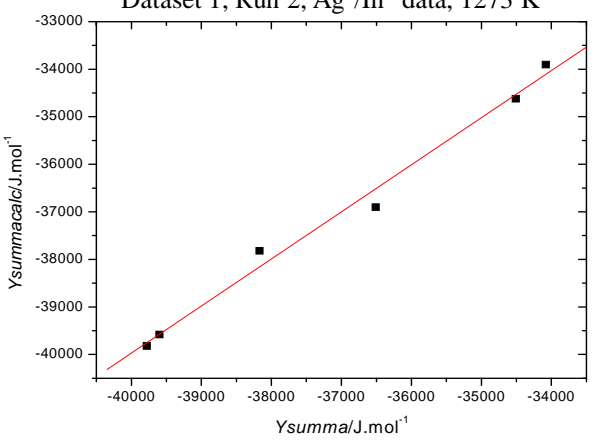

using Miki et al.'s raw $\mathrm{Ag}^{+} / \mathrm{In}^{+}$data, $1273 \mathrm{~K}$

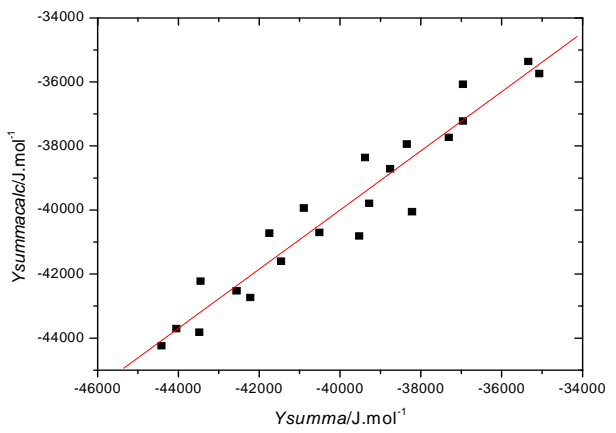

Fig. (3). Ysummacalc as a function of Ysumma of Ag-In-Sn [2], obtained from all of our Runs and also from Miki et al.,'s [5] raw data at $1273 \mathrm{~K}$.
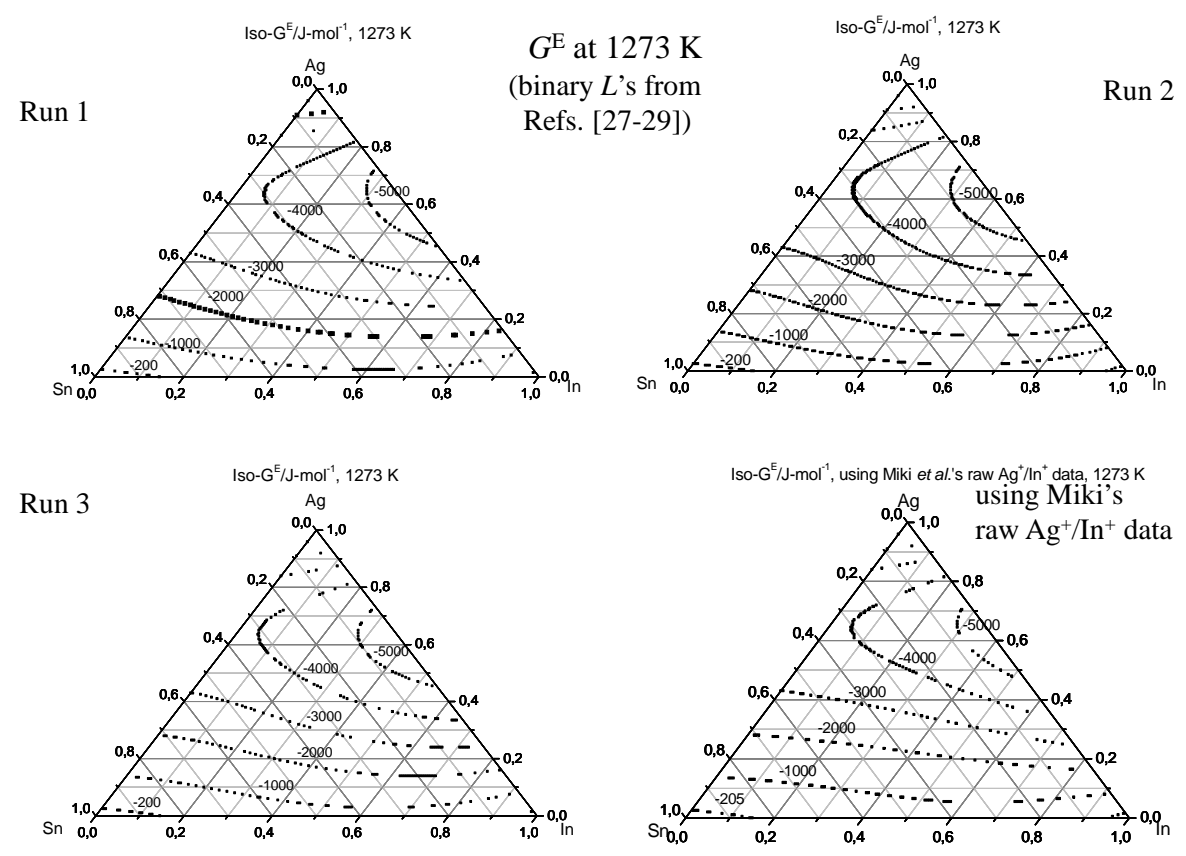

Fig. (4). The iso-excess Gibbs energy curves obtained from Runs 1, 2 and 3, as well as from Miki et al.,'s [5] raw data at 1273 K, using the same binary $L$-parameters from Refs. [27-29].

During the study of the Al-Cu-Sn system [3] all the three ion-intensity ratio methods (' $\mathrm{Al} / \mathrm{Sn}{ }^{+},,{ }^{\prime} \mathrm{Al} / \mathrm{Cu}^{+}$, and ' $\mathrm{Cu} u^{+} / \mathrm{Sn}^{+}$) were applied. Figs. ( 2 and 3 ) show the relations for the example of both Al-Cu-Sn [3] and Ag-In-Sn [2] systems, respectively. In order to show the correlation of the data, as a graph, (though four dimensions are required) in addition to calculating the correlation coefficient of the multi-linear four-dimensional regression, appropriate two- dimensional functions were obtained and plotted to visualise the quality of the regression. Figs. (2 and 3) show Ysummacalc (the recalculated Ysumma by the use of ternary parameters obtained in equations (13), (14) and (24) against Ysumma for two or more ion-intensity ratio methods. In the case that the fitting is accurate Ysummacalc should agree with Ysumma and a perfect correlation should be obtained. It can be seen that, though theoretically all three ion-intensity 


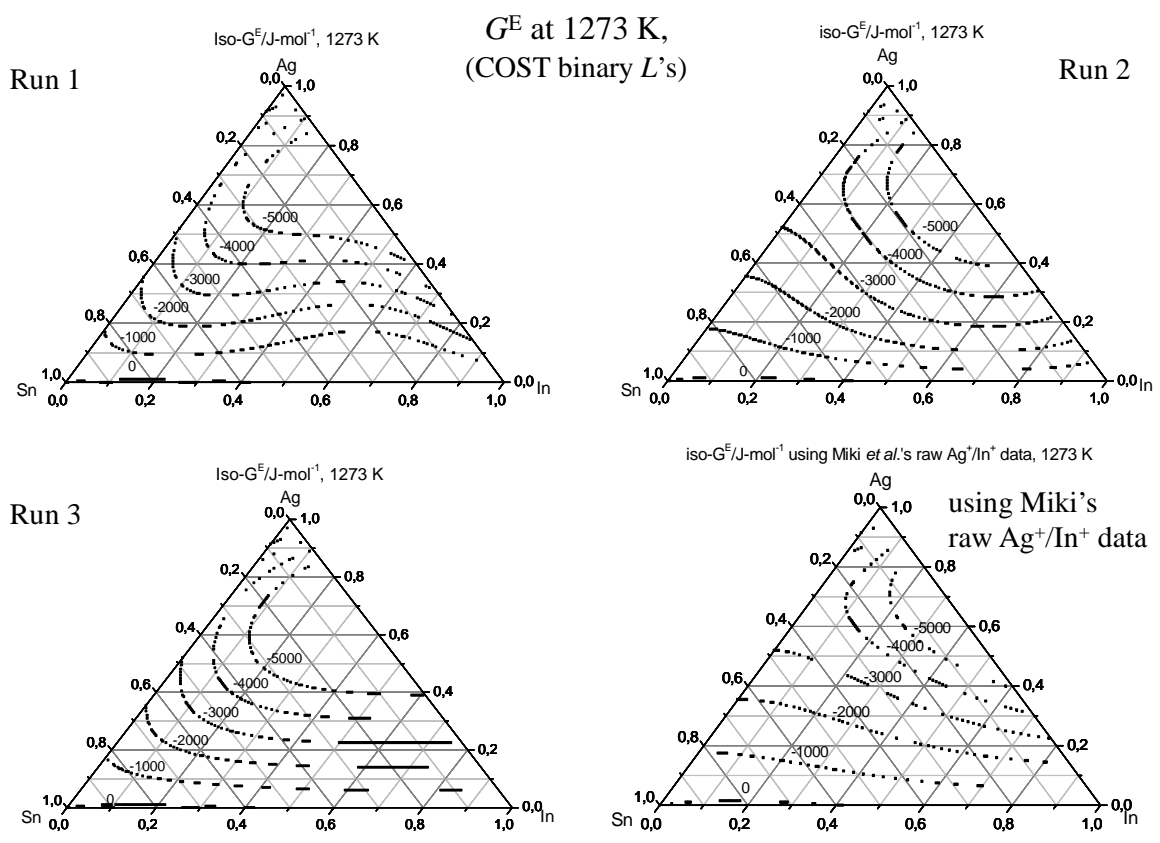

Fig. (5). The iso-excess Gibbs energy curves obtained from Runs 1-3, as well as from Miki et al.'s [5] raw data at 1273 K, using the same COST 531 [25] binary L-parameters.

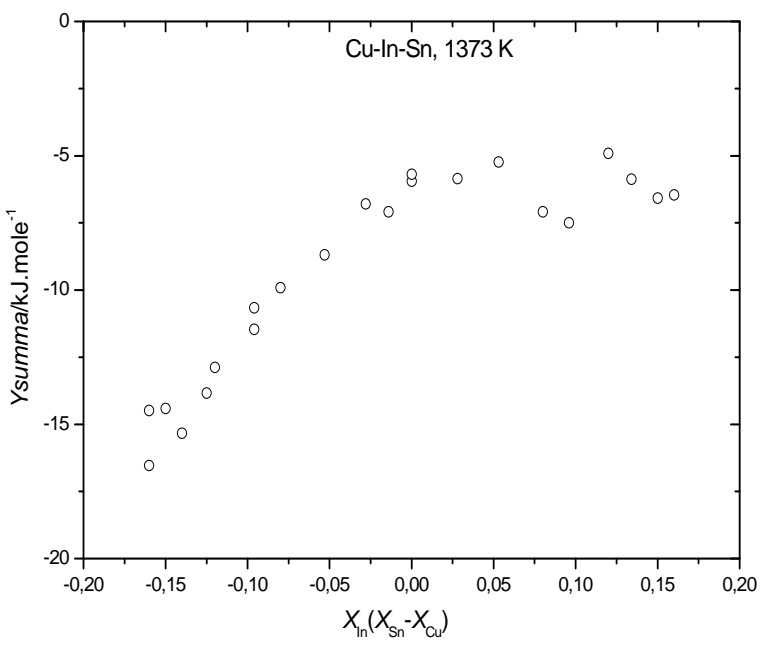

Fig. (6). Ysumma as a function of $X_{\mathrm{In}}\left(X_{\mathrm{Sn}}-X_{\mathrm{Cu}}\right)$ at $1373 \mathrm{~K}$ for Cu-InSn [1] system.

ratio variations should provide the same results, due to the higher scatter in the $\mathrm{Al}^{+}$intensity data, the $\mathrm{Cu}^{+} / \mathrm{Sn}^{+}$ionintensity ratio proved to be the most optimal for the calculation of the results. More details can be seen in the source papers $[3,2]$.

Furthermore, we had to decide which of the input binary $L$-data-sets, either the consistent COST 531 [25] binary datasets or alternative literature or our own binary databases, to use for calculating the values of $Y$ and Ysumma. (The latter quantity, beside $Y Y$ includes the quantity of $Y$ as well, as can be seen above.). The effect of the binary database, e.g., for the Ag-In-Sn system [2], can be clearly seen in Figs. (4 and 5). It is clear that the obtained excess Gibbs energy evaluated from our different measurement runs shows a very good agreement in the case of using the data of Ref. [27-29] concerning the boundary binary systems. In contrast, when the binary data of Ref. [25] are used for the evaluation of $Y$ and Ysumma the agreement between the individual runs is much worse. The definite difference between the two sources of binary data can be better seen in the source paper [2]. Certainly not only our own measured ternary data but also the literature binary alloy input data have an effect on the quality of the ternary data obtained by multiple regressions.

A further test was made to check whether the three ternary $L$-parameters are equal, as Miki et al., [5] assumed for the AgIn-Sn system, or different. In addition to the regressions performed by Eqns. (18), (19) and (28) the equality of the three parameters can also be checked by assuming it and by plotting the resulting function. If the ternary $L$-parameters are really equal, e.g., Eqn. (13) should change to

$Y_{\text {summa }}{ }_{\mathrm{ABC}\left(\mathrm{A}^{+} / \mathrm{C}^{+}\right)}=-C_{\mathrm{ABC}\left(\mathrm{A}^{+} / \mathrm{C}^{+}\right)}+L_{\mathrm{ABC}}\left(X_{\mathrm{C}}-X_{\mathrm{A}}\right) X_{\mathrm{B}}(42)$

As an example, by plotting $Y_{\text {summa }} a_{\mathrm{CulnSn}\left(\mathrm{Cu}^{+} / \mathrm{Sn}^{+}\right)}$as a function of $\left(X_{\mathrm{Sn}}-X_{\mathrm{Cu}}\right) X_{\mathrm{In}}$, according to Eqn. (42) a straight line with a relatively small scatter should be obtained if the equality of the ternary $L$-parameters is true. In contrast, as can be seen in Fig. (6), a definitely curved function can be seen, which excludes the assumption of equality. In contrast, for the Ag-In-Sn system, the three ternary $L$-parameters are closer to each other. In addition, if the three ternary $L$ parameters are equal, the ternary interaction part $\left[X_{\mathrm{A}} X_{\mathrm{B}} X_{\mathrm{C}}\left(L_{\mathrm{ABC}}^{(0)} X_{\mathrm{A}}+L_{\mathrm{ABC}}^{(1)} X_{\mathrm{B}}+L_{\mathrm{ABC}}^{(2)} X_{\mathrm{C}}\right)\right]$ of $G^{\mathrm{E}}$ in Eqn. (2) will also change to $X_{\mathrm{A}} X_{\mathrm{B}} X_{\mathrm{C}} L_{\mathrm{ABC}}$ causing symmetric iso-lines of this quantity when we plot it in the ternary composition diagram. In contrast, these iso-lines are usually not 


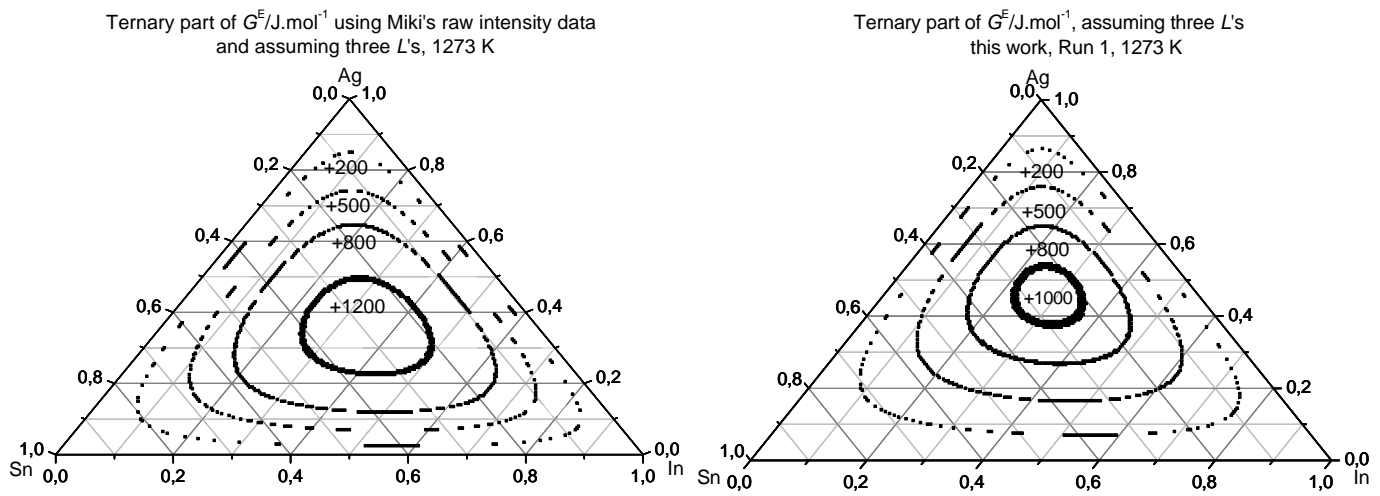

Fig. (7). The iso-curves of the ternary interaction part of the excess Gibbs energy in the Ag-In-Sn system [2] at 1273 K, obtained in this work from the data of Run 1 and from Miki et al.'s [5] raw data.

symmetrical. The asymmetry can be seen for the corresponding function of the Al-Cu-Sn system [3] and the relative symmetry can be seen for the Ag-In-Sn system [2] in Figs. (1 and 7).
As a final test, the obtained RKM-KEMS data should be compared to the model-free, pure experimental KEMS data in order to confirm or reject the RKM-KEMS data. A comparison between the RKM and IEM-VDA data of the Al-Cu-Sn system [3] can be seen in Table 2.

Table 2. Activities of some Selected Al-Cu-Sn [3] Compositions Determined by Both IEM-VD and RKM Methods at $1453 \mathrm{~K}$ in the IEM-VD Experiments. The Estimated Uncertainty in the RKM Activity Data is Below 5\%

\begin{tabular}{|c|c|c|c|c|c|c|c|c|c|c|}
\hline Composition & Run & $\begin{array}{l}\text { Clausing } \\
\text { Factor }\end{array}$ & $\begin{array}{c}\text { Orifice } \\
\text { Diameter }\end{array}$ & Temperature & $\begin{array}{l}\text { Evap. } \\
\text { Time }\end{array}$ & $\begin{array}{c}\text { Total } \\
\text { Mass Loss }\end{array}$ & $\begin{array}{l}\text { Total Mass } \\
\text { Loss Rate }\end{array}$ & $a_{\mathrm{Al}}$ & $a_{\mathrm{Cu}}$ & $a_{\mathrm{Sn}}$ \\
\hline & & & $\mathrm{mm}$ & K & $\mathrm{h}$ & $\mathrm{mg}$ & $\mathrm{mg} / \mathrm{h}$ & $\begin{array}{c}\text { NAA(ICP- } \\
\text { AOS) } \\
{[\mathrm{RKM}]}\end{array}$ & $\begin{array}{c}\text { NAA(ICP- } \\
\text { AOS) } \\
{[\mathrm{RKM}]}\end{array}$ & $\begin{array}{c}\text { NAA(ICP- } \\
\text { AOS) } \\
{[\mathrm{RKM}]}\end{array}$ \\
\hline $\mathrm{Al}_{0.225} \mathrm{Cu}_{0.7} \mathrm{Sn}_{0.075}$ & $\mathrm{a}$ & 1.00 & 0.90 & 1453 & 22.63 & 9.82 & 0.4339 & - & & - \\
\hline $\mathrm{Al}_{0.225} \mathrm{Cu}_{0.7} \mathrm{Sn}_{0.075}$ & $\mathrm{~b}$ & 1.00 & 0.90 & 1453 & 21.72 & 9.86 & 0.4540 & - & & - \\
\hline $\mathrm{Al}_{0.225} \mathrm{Cu}_{0.7} \mathrm{Sn}_{0.075}$ & $\begin{array}{l}\text { Sum } \\
\text { mean }\end{array}$ & 1.00 & 0.90 & 1453 & 44.35 & 19.68 & $\begin{array}{c}0.4437 \\
0.4440 \pm 0.0143\end{array}$ & $\begin{array}{c}\text { 0.0285(0.0189) } \\
\text { [RKM:0.029] }\end{array}$ & $\begin{array}{l}0.449(0.458) \\
{[\text { RKM:0.358] }}\end{array}$ & $\begin{array}{l}0.154(0.155) \\
{[\text { RKM:0.156] }}\end{array}$ \\
\hline $\mathrm{Al}_{0.2} \mathrm{Cu}_{0.6} \mathrm{Sn}_{0.2}$ & $\mathrm{a}$ & 0.42 & 0.50 & 1453 & 65.00 & 4.61 & 0.0709 & & & \\
\hline $\mathrm{Al}_{0.2} \mathrm{Cu}_{0.6} \mathrm{Sn}_{0.2}$ & $\mathrm{~b}$ & 0.42 & 0.50 & 1453 & 67.27 & 5.12 & 0.0761 & & & \\
\hline $\mathrm{Al}_{0.2} \mathrm{Cu}_{0.6} \mathrm{Sn}_{0.2}$ & $\begin{array}{l}\text { Sum } \\
\text { mean }\end{array}$ & 0.42 & 0.50 & 1453 & 132.27 & 9.73 & $\begin{array}{c}0.0736 \\
0.0735 \pm 0.0037\end{array}$ & $\begin{array}{c}0.0305(0.0368) \\
{[\text { RKM:0.054] }}\end{array}$ & $\begin{array}{l}0.229(0.263) \\
{[\text { RKM:0.250] }}\end{array}$ & $\begin{array}{l}0.347(0.331) \\
\text { [RKM:0.353] }\end{array}$ \\
\hline $\mathrm{Al}_{0.2} \mathrm{Cu}_{0.6} \mathrm{Sn}_{0.2}$ & $\mathrm{a}$ & 1.00 & 0.90 & 1453 & 19.05 & 12.25 & 0.6430 & - & & - \\
\hline $\mathrm{Al}_{0.2} \mathrm{Cu}_{0.6} \mathrm{Sn}_{0.2}$ & $\mathrm{~b}$ & 1.00 & 0.90 & 1453 & 20.62 & 13.06 & 0.6335 & - & & - \\
\hline $\mathrm{Al}_{0.2} \mathrm{Cu}_{0.6} \mathrm{Sn}_{0.2}$ & $\begin{array}{l}\text { Sum } \\
\text { mean }\end{array}$ & 1.00 & 0.90 & 1453 & 39.67 & 25.31 & $\begin{array}{c}0.6381 \\
0.6383 \pm 0.0068\end{array}$ & $\begin{array}{c}\text { 0.0414(0.0384) } \\
\text { [RKM:0.054] }\end{array}$ & $\begin{array}{l}0.285(0.302) \\
{[R K M: 0.250]}\end{array}$ & $\begin{array}{l}\text { 0.375(0.369) } \\
\text { [RKM:0.353] }\end{array}$ \\
\hline $\mathrm{Al}_{1 / 3} \mathrm{Cu}_{1 / 3} \mathrm{Sn}_{1 / 3}$ & $\mathrm{a}$ & 0.42 & 0.50 & 1453 & 23.00 & 2.46 & 0.1070 & - & & - \\
\hline $\mathrm{Al}_{1 / 3} \mathrm{Cu}_{1 / 3} \mathrm{Sn}_{1 / 3}$ & $\mathrm{~b}$ & 0.42 & 0.50 & 1453 & 24.25 & 2.41 & 0.0994 & - & & - \\
\hline $\mathrm{Al}_{1 / 3} \mathrm{Cu}_{1 / 3} \mathrm{Sn}_{1 / 3}$ & $\mathrm{c}$ & 0.42 & 0.50 & 1453 & 26.83 & 2.26 & 0.0842 & - & & - \\
\hline $\mathrm{Al}_{1 / 3} \mathrm{Cu}_{1 / 3} \mathrm{Sn}_{1 / 3}$ & d & 0.42 & 0.50 & 1453 & 46.27 & 4.21 & 0.0910 & & & \\
\hline $\mathrm{Al}_{1 / 3} \mathrm{Cu}_{1 / 3} \mathrm{Sn}_{1 / 3}$ & $\begin{array}{l}\text { Sum } \\
\text { mean }\end{array}$ & 0.42 & 0.50 & 1453 & 120.35 & 11.34 & $\begin{array}{c}0.0942 \\
0.0954 \pm 0.0099\end{array}$ & $\begin{array}{c}0.110 \\
\text { [RKM:0.232] }\end{array}$ & $\begin{array}{c}0.110 \\
\text { [RKM:0.087] }\end{array}$ & $\begin{array}{c}0.488 \\
{[\text { RKM:0.574] }}\end{array}$ \\
\hline $\mathrm{Al}_{1 / 3} \mathrm{Cu}_{1 / 3} \mathrm{Sn}_{1 / 3}$ & $\mathrm{a}$ & 1.00 & 0.90 & 1453 & 13.08 & 12.21 & 0.9332 & & & \\
\hline $\mathrm{Al}_{1 / 3} \mathrm{Cu}_{1 / 3} \mathrm{Sn}_{1 / 3}$ & $\mathrm{~b}$ & 1.00 & 0.90 & 1453 & 10.97 & 10.28 & 0.9374 & & & \\
\hline $\mathrm{Al}_{1 / 3} \mathrm{Cu}_{1 / 3} \mathrm{Sn}_{1 / 3}$ & $\mathrm{c}$ & 1.00 & 0.90 & 1453 & 12.00 & 11.21 & 0.9342 & & & \\
\hline $\mathrm{Al}_{1 / 3} \mathrm{Cu}_{1 / 3} \mathrm{Sn}_{1 / 3}$ & $\begin{array}{l}\text { Sum } \\
\text { mean }\end{array}$ & 1.00 & 0.90 & 1453 & 36.05 & 33.70 & $\begin{array}{c}0.9348 \\
0.9349 \pm 0.0022\end{array}$ & $\begin{array}{l}0.179(0.203) \\
{[R K M: 0.232]}\end{array}$ & $\begin{array}{l}0.096(0.102) \\
{[\text { RKM:0.087] }}\end{array}$ & $\begin{array}{c}0.629(0.614) \\
{[\text { RKM:0.574] }}\end{array}$ \\
\hline
\end{tabular}

The activity data, obtained using the analytical data of ICP-AOS, are in parentheses whereas the values obtained using NAA stand in front of the parentheses. The corresponding data provided by the RKM method are in [ ] brackets for comparison. 
Further details can be seen in the source papers [1-4].

\section{ACKNOWLEDGEMENTS}

The financial support of Slovenian Research Agency is gratefully acknowledged. This work is a contribution to the European COST MP0602 Action on "Advanced Solder Materials for High Temperature Application (HISOLD)". Laszlo Bencze wishes to thank for the COST-support of the short-term scientific mission trips (STSM) in the framework of this action.

\section{CONFLICT OF INTEREST}

The authors confirm that this article content has no conflicts of interest.

\section{REFERENCES}

[1] Popovic, L. Bencze, "Mass spectrometric determination of ternary interaction parameters of liquid Cu-In-Sn alloy," International Journal of Mass Spectrometry, vol. 257, pp. 41-49, 2006.

[2] L. Bencze, A. Popovic, "Knudsen effusion mass spectrometric determination of mixing thermodynamic data of liquid Ag-In-Sn alloy," International Journal of Mass Spectrometry, vol. 270, pp. 139-155, 2008.

[3] L. Bencze, R. Milačič, R. Jaćimović, D. Žigon, L. Mátyás, A. Popovi č, "Knudsen effusion mass spectrometric determination of mixing thermodynamic data of liquid $\mathrm{Al}-\mathrm{Cu}-\mathrm{Sn}$ alloy," International Journal of Mass Spectrometry, vol. 289, pp. 11-29, 2010.

[4] J. Romanowska, L. Bencze, A. Popović, "Thermodynamic properties of liquid $\mathrm{Cu}-\mathrm{Sb}-\mathrm{Sn}$ alloys by equilibrium saturation and Knudsen effusion mass spectrometric methods," Archieves of Materials Science and Engineering, vol. 39, pp. 69-74, 2009.

[5] T. Miki, N. Ogawa, T. Nagasaka, M. Hino, "Activity measurement of the constituents in molten Ag-In-Sn ternary alloy by Mass Spectrometry," Materials Transactions, vol. 42, pp. 732-738, 2001.

[6] H. Schmidt, J. Tomiska, "Mass spectrometric determination of the thermodynamic excess properties of ternary $\mathrm{Fe}-\mathrm{Co}-\mathrm{Cr}$ melts," Journals of Alloys and Compounds, vol. 385, pp. 126-132, 2004.

[7] O. Kubaschewski and C.B. Alcock, "A relationship between segregated Arsenic in gas and photoluminescence and kinetics of arsenic segregation at room temperature," Metallurgical Thermochemistry, $5^{\text {th }}$ Ed., Pergamon Press Ltd.: UK, 1979.

[8] P. Chartrand and A. D. Pelton, "On the choice of "Geometric" thermodynamic models", Journal of Phase Equilibria, vol. 21, pp. 141-147, 2000.

[9] D. Živkovi č, ž. Živkovi č and Y-H. Liu, "Comparative study of thermodynamic predicting methods applied to the $\mathrm{Pb}-\mathrm{Zn}-\mathrm{Ag}$ system," Journals of Alloys and Compounds, vol. 265, pp. 176-184, 1998.

[10] D. Goodman, "Thermodynamic models of multi component Sodium alloys" In: High Temperature Lamp Chemistry. Ed. E. G. Zubler, Electrochemical Society: NJ, 1985, pp. 194-204.

[11] J. Drowart, C. Chatillon, J. Hastie, D. Bonnell, "High temprature mass spectrometry: instrumental techniques, ionization crosssections, pressure managements and thermodynamics data", Pure and Applied Chemistry IUPAC-Technical Report, vol. 77, pp. 683737, 2005.
[12] A. Popovic, "Mass spectrometric determination of the ionisation cross-sections of $\mathrm{BaO}, \mathrm{Ba}, \mathrm{BaF} 2$ and $\mathrm{Ba} 2$ by electron impact", International Journal of Mass Spectrometry, vol. 230, pp. 99-112, 2003.

[13] G.R. Belton, R.J. Fruehan, "The determination of activities by Mass Spectrometry. I. The Liquid Metallic Systems Iron-Nickel and Iron-Cobalt," Metallurgical and Materials Transactions, vol. 71, pp. 1403, 1967.

[14] Y.M. Muggianu, M. Gambino, L.P. Bros, "Enth alpies of formation of liquid alloys bismuth gallium tin at $723 \mathrm{~K}$ choice of an analytical representation of integral and partial thermodynamic functions of mixing for this ternary system," Journal of Chemical Physics, vol. 72, pp. 85-88, 1975.

[15] K.L. Bell, H.B. Gilbody, J.G.Hughes, A.E. Kingston, F.J. Smith, "Recommended data on electron impact ionization of light atoms and ions," The Journal of Physical and Chemical, vol. 12, pp. 891916, 1983.

[16] M.A. Lennon, K.L. Bell, H.B. Gilbody, J.G. Hughes, A.E. Kingston, M.J. Murray, F.J. Smith, "Recommended data on the electron impact ionization of atoms and ions: Fluorine to Nickel," Journal of Physical Chemistry Reference Data, vol. 17, pp. 12851363, 1988.

[17] J.B. Mann, "Ionization Cross Sections of the Elements Calculated from Mean Square Radii of Atomic Orbitals," Journal of Chemical Physics, vol. 46, pp. 1646, 1967.

[18] J.W. Otvos, D.P. Stevenson, "Cross-sections of Molecules for Ionization by Electrons," Journal of the American Chemical Society, vol. 78; no. 546, 1956

[19] R.S. Freund, R.C. Wetzel, R.J. Shul, T.R. Hayes, "Near-threshold electron-impact ionization of magnesium," Physical Review, vol 41, pp. 3575,1990 .

[20] L. Sidorov and M. V. Korobov, "Mass Spectrometric Determination of Activity in Molten Salt Mixtures," Mass Spectroscopy, vol. 29, pp. 199-219, 1981.

[21] K. Hilpert: "Chemistry of Inorganic vapours", In: Structure and Bonding, Springer Verlag: UK, vol. 73, pp. 97 -198, 1990.

[22] G.R. Belton, R.J. Fruehan, "A study of austenite precipitate growth in duplex stainless steel," Metallurgical and Materials Transactions, vol. 1, pp. 781, 1970.

[23] L. Bencze, T. Markus, S. Dash, D.D. Raj, D. Kath, W.A. Oates, W. Löser, K. Hilpert, "Preparation of polybenzoxazole fibers via electrospinning," Metallurgical and Materials Transactions, A, vol. 237, pp. 3171-3181, 2006.

[24] Ansara, A.T. Dinsdale, M.H. Rand (eds.) Thermochemical database for light metal alloys, vol. 2, Office for Official Publications of the European Communities, Luxembourg, 1998, ISBN 92-828-3902-8 or Report No. EUR 18499.

[25] A.T. Dinsdale, A. Watson, A. Kroupa, J. Vreštál, A. Zemanová and J. Vízdal, "Atlas of Phase Diagrams for Lead-Free Soldering", C COST Office, ISBN 978-80-86292-28-1. or COST 531 Thermodynamic Database v. 2.0.

[26] J. Miettinen, "Thermodynamic description of the Cu-Al-Sn system in the copper-rich corner," Metallurgical and Materials Transactions A, vol. 33, pp. 1639-1648, 2002.

[27] T. Yamaji, E. Kato, "Morphology of tin dendrites in near-eutectic alloys," Metallurgical and Materials Transactions, vol. 3, pp. $1002,1972$.

[28] G. Qi, M. Hino, T. Azakami, "Thermodynamic study of liquid AgIn and Ag-Ga alloys with a Knudsen Cell-Mass Spectrometer," Materials Transactions, vol. JIM 30, pp. 575, 1989.

[29] B.J. Lee, C.S. Oh, J.H. Shim, "Thermodynamic assessments of the Sn-In and Sn-Bi binary systems," Journal of Electronic Materials. vol. 25 , p. 983, 1996. 